\title{
Description and applications of a mobile system performing on-road aerosol remote sensing and in situ measurements
}

\author{
Ioana Elisabeta Popovici ${ }^{1,2}$, Philippe Goloub ${ }^{1}$, Thierry Podvin ${ }^{1}$, Luc Blarel $^{1}$, Rodrigue Loisil $^{1}$, Florin Unga ${ }^{1}$, \\ Augustin Mortier ${ }^{3}$, Christine Deroo ${ }^{1}$, Stéphane Victori ${ }^{2}$, Fabrice Ducos ${ }^{1}$, Benjamin Torres ${ }^{4,1}$, Cyril Delegove ${ }^{1}$, \\ Marie Choël ${ }^{5}$, Nathalie Pujol-Söhne ${ }^{6}$, and Christophe Pietras ${ }^{7}$ \\ ${ }^{1}$ Univ. Lille, CNRS, UMR8518 - LOA - Laboratoire d'Optique Atmosphérique, 59000 Lille, France \\ ${ }^{2}$ R\&D Department, Cimel Electronique, 75011 Paris, France \\ ${ }^{3}$ Division for Climate Modelling and Air Pollution, Norwegian Meteorological Institute, 0313 Oslo, Norway \\ ${ }^{4}$ GRASP-SAS, Remote sensing developments, Univ. Lille, 59650 Villeneuve d'Ascq, France \\ ${ }^{5}$ Univ. Lille, CNRS, UMR8516 - LASIR - Laboratoire de Spectrochimie Infrarouge et Raman, 59000 Lille, France \\ ${ }^{6}$ Modelling Department, ATMO Hauts-de-France, 59000 Lille, France \\ ${ }^{7}$ Ecole Polytéchnique, CNRS, Laboratoire de Météorologie Dynamique, 91120 Palaiseau, France
}

Correspondence: Ioana Elisabeta Popovici (ie.popovici@ed.univ-lille1.fr)

Received: 31 March 2018 - Discussion started: 4 April 2018

Revised: 3 July 2018 - Accepted: 10 July 2018 - Published: 9 August 2018

\begin{abstract}
The majority of ground-based aerosols observations are limited to fixed locations, narrowing the knowledge on their spatial variability. In order to overcome this issue, a compact Mobile Aerosol Monitoring System (MAMS) was developed to explore the aerosol vertical and spatial variability. This mobile laboratory is equipped with a micropulse lidar, a sun photometer and an aerosol spectrometer. It is distinguished from other transportable platforms through its ability to perform on-road measurements and its unique feature lies in the sun photometer's capacity for tracking the sun during motion. The system presents a great flexibility, being able to respond quickly in case of sudden aerosol events such as pollution episodes, dust, fire or volcano outbreaks. Onroad mapping of aerosol physical parameters such as attenuated aerosol backscatter, aerosol optical depth, particle number and mass concentration and size distribution is achieved through the MAMS. The performance of remote sensing instruments on-board has been evaluated through intercomparison with instruments in reference networks (i.e. AERONET and EARLINET), showing that the system is capable of providing high quality data. This also illustrates the application of such a system for instrument intercomparison field campaigns. Applications of the mobile system have been exemplified through two case studies in northern France. MODIS AOD data was compared to ground-based mobile sun pho-
\end{abstract}

tometer data. A good correlation was observed with $R^{2}$ of 0.76 , showing the usefulness of the mobile system for validation of satellite-derived products. The performance of BSCDREAM8b dust model has been tested by comparison of results from simulations for the lidar-sun-photometer derived extinction coefficient and mass concentration profiles. The comparison indicated that observations and the model are in good agreement in describing the vertical variability of dust layers. Moreover, on-road measurements of $\mathrm{PM}_{10}$ were compared with modelled $\mathrm{PM}_{10}$ concentrations and with ATMO Hauts-de-France and AIRPARIF air quality in situ measurements, presenting an excellent agreement in horizontal spatial representativity of $\mathrm{PM}_{10}$. This proves a possible application of mobile platforms for evaluating the chemistry-models performances.

\section{Introduction}

Aerosols are a variable component of the atmosphere impacting air quality and climate. In order to monitor the atmospheric aerosols, independent ground-based observations are performed globally, grouped in large networks, such as the Aerosol Robotic Network (AERONET; Holben et al., 1998), the Micropulse Lidar Network (MPLNET; Wel- 
ton et al., 2005), and the EARLINET/ACTRIS (Aerosol, Clouds and Trace gases Research Infrastructure Network; Pappalardo et al., 2014), or organised in national surface networks, dedicated to air quality monitoring (ATMO France, http://www.atmo-france.org/, last access: 30 March 2018). Such observations offer capabilities for long-term monitoring of aerosol properties and evaluation of trends, but they are limited over fixed locations. Lidar is an excellent tool for studying the height-resolved aerosol characteristics, especially interesting for pollution episodes and long-range transport situations. Such observations of vertical aerosol structures and quantification of their contribution to the total column aerosol content are important as the lifetime of particles in the free troposphere is of the order of weeks. Furthermore, concentrations at surface level can sometimes be influenced by the subsidence of transported aerosols from the free troposphere. Thus, the knowledge of the vertical distribution, as close to the surface as possible, of aerosols optical properties, is required to precisely predict aerosol concentrations, especially for air quality models. Gravimetric measurements of particles mass concentration at surface level are sparse within the territory, which directs us to the alternative of using optical aerosol properties to estimate their vertically resolved mass concentration and to get as accurate estimates as possible for particle concentration at surface level. This direction is a challenge, as it requires information on aerosol chemical and microphysical properties. Nevertheless, in this work we exemplify this direction on mobile measurements.

Existing lidar networks consist of systems with various configurations, from single-wavelength elastic to multiwavelength Raman lidar. Most of them are complex instruments that require regular maintenance and a controlled environment for their operation, so they are predominantly installed in laboratory rooms. Therefore, their use for atmospheric profiling is limited over a fixed location. Nevertheless, the aerosol distribution is highly variable spatially in case of sudden events; e.g. pollution episodes, dust and fire outbreaks, volcano eruptions, long-range transports and dispersion of pollutants from emission sources. In these situations, field observations are important, as the spatial variability is impossible to assess from point measurements. Mobile observations are one of the best solutions to map the extent of such events and to study the regional gradients in aerosol concentrations. If lidar could be easily deployed at the time needed, the number of applications would rapidly increase, from the validation of satellite measurements and model predictions to the investigation of pollutants dynamics and quantification of diffuse emissions at industrial sites.

A number of mobile on-road experiments focused on the spatial variability of the particle number and mass concentration along highways in Jordan (Hussein et al., 2017), in Noord Holland (Weijers et al., 2004) and in an Alpine Valley (Weimer et al., 2009), of black carbon and particulate sulfate concentrations from Mainz, Germany to southern Spain (Drewnick et al., 2012) and of aerosol and gas phase am- bient concentrations in Zurich, Switzerland (Bukowiecki et al., 2002). Other studies investigated the tropospheric trace gas distribution: $\mathrm{NO}_{2}$ along the Brussels-Heidelberg transect (Wagner et al., 2010), $\mathrm{SO}_{2}$ and $\mathrm{NO}_{2}$ in Guangzhou, China (Wu et al., 2013) and $\mathrm{CO}_{2}$ and $\mathrm{CH}_{4}$ in Utah, USA (Bush et al., 2015). Remote sensing instruments are less involved in mobile applications due to their size, operation cautions and sensitivity to misalignment due to movement. Mobile sun photometer measurements on ship cruises are performed with Microtops II handheld sun photometers in the framework of the Maritime Aerosol Network (MAN; Smirnov et al., 2009), a component of AERONET, dedicated to collect aerosol optical depth data over oceans. In the early developments of our mobile system, a Microtops II sun photometer was used. Other mobile sun photometer measurements have been reported by Lewandowski et al. (2010), but they refer to stationary measurements at different points along the road, the sun photometer being installed on the roof of the vehicle for the measurements and taken down during travel. The first evidence of continuous mobile sun photometer measurements during vehicle's movement has been presented by Mortier (2012) during the DRAGON (Distributed Regional Aerosol Gridded Observation Networks; (Holben et al., unpublished) - USA campaign. For lidar, the term "mobile" refers mostly to scanning (Chiang et al., 2015; Marchant, 2009), transportable (Berkhout et al., 2016; Chazette et al., 2014; Freudenthaler et al., 2002) or scanning and transportable (Dou et al., 2014) systems, used for measurements in remote places, during field campaigns or simply outside laboratory rooms. To our knowledge, only a few studies presenting ground-based lidar profiling of aerosol properties by on-road mobile measurements have been conducted, over Paris agglomeration (Pal et al., 2012; Raut and Chazette, 2009; Royer et al., 2011), on London's orbital motorway (Raut et al., 2009) and from Paris to Siberia (Dieudonné et al., 2015). Thus, we consider that the capability of deploying remote sensing instruments for on-road mapping of aerosol properties is not explored enough. For the first time, the description of a compact mobile system performing on-road measurements with a lidar, a sun photometer and an aerosol spectrometer is presented here. The uniqueness of the system lies mainly in the sun photometer, capable to track the sun during vehicle's motion, and in the synergy of lidar and sun photometer measurements to derive aerosol optical properties profiles along the investigated route.

The main objective of this paper is to show the potential of a mobile platform performing on-road remote sensing and in situ measurements to derive aerosol properties. The use of the mobile system for atmospheric studies is versatile, some of its possible applications being emphasized throughout this study. Section 2 presents the mobile system and the instrumentation integrated in the payload as well as the data processing and quality assurance procedures. The methodology used to derive aerosol properties from remote sensing measurements and discussions on uncertainties are included 
in each part. Furthermore, intercomparisons with reference instruments are performed and are presented in Sect. 2. In Sect. 3 two case studies using data from mobile campaigns in northern France and Paris are presented, examples that illustrate the capability of our system to evaluate the mass concentration both vertically resolved and at surface level. In addition, at surface level, the lidar-derived mass concentrations are compared to air quality stations measurements and to modelled $\mathrm{PM}_{10}$ concentrations. Section 4 summarises the status, applications and potential developments of the mobile system. The last section (Sect. 5) is dedicated to conclusions.

\section{Instruments, methodology and data quality}

This section is divided into four parts, each focused on a component of the mobile system: the mobile system as a whole (Sect. 2.1), the lidar (Sect. 2.2), the mobile sun photometer (Sect. 2.3) and the particle sizer (Sect. 2.4). For each component, details of the pre-processing and data quality assurance procedures for lidar and sun photometer measurements are given. Comparisons with instruments from reference networks such as EARLINET (European Aerosol Research Lidar Network) and AERONET (Aerosol Robotic Network) are also included in each section. The principle of inversion algorithms used to derive aerosol microphysical and optical properties such as volume size distribution, extinction coefficient, effective extinction-to-backscatter ratio and mass concentration are described. Finally, uncertainties are discussed in each part.

\subsection{Description of the mobile system}

Most instruments set up on mobile platforms and deployed in field campaigns are bulky systems, requiring large vehicles for their installation and transportation. As compared to such systems, the MAMS (Mobile Aerosol Monitoring System) is more compact and robust. The mobile laboratory described here is a minivan equipped with a micro-pulse lidar, a sun photometer and an aerosol spectrometer (Fig. 1). The minivan is a Renault Kangoo Intens Energy $115 \mathrm{CH}$ CO2 $140 \mathrm{~g} \mathrm{~km}^{-1}$ (length: $4.21 \mathrm{~m}$, width: $1.83 \mathrm{~m}$, total height: $1.87 \mathrm{~m}$ ). A car with a gasoline engine was chosen against one on diesel due to lower particle emissions and against an electric car due to higher autonomy (around $500 \mathrm{~km}$ ). The vehicle's boot and the rear part of the roof have been modified to allow the installation of instruments inside and on top of the vehicle. In order to minimise shocks and vibrations on the instruments while driving, the rear wheels are equipped with coil suspension and instruments are equipped with shockabsorbing devices. For lidar measurements, a $350 \times 250 \mathrm{~mm}$ anti-reflective glass of $8 \mathrm{~mm}$ thickness type Conduran magic, that has a transmission $>90 \%$ for $532 \mathrm{~nm}$, has been embedded in the rear-part of the car's roof. In order to continuously operate the instruments, a 12 V/300 Ah AGM battery

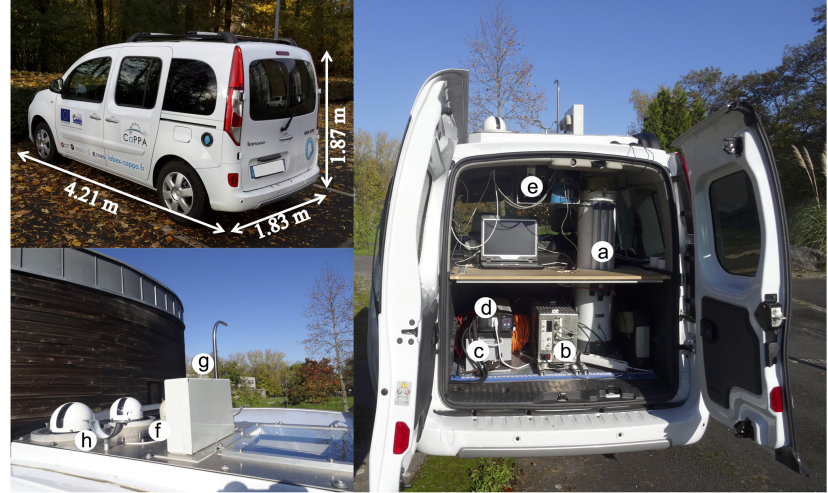

Figure 1. Mobile system and equipment: (a) lidar transmitterreceiver optical head, (b) lidar control and acquisition unit, (c) battery, (d) sine-wave inverter charger, (e) aerosol spectrometer, (f) meteorological probe, $(\mathrm{g})$ isokinetic sampling probe and (h) PLASMA sun photometers.

and a sine-wave inverter-charger are mounted in the vehicle. With a power consumption of $100 \mathrm{~W}$, an autonomy of $29 \mathrm{~h}$ can be ensured for continuous measurements. The vehicle is also equipped with an electrical installation and an external outlet used for charging the battery. During stationary measurements, the battery is fed and recharged using the external outlet. The total payload including measurement equipment, battery and inverter is approximately $130 \mathrm{~kg}$.

The real-time geolocation, altitude and driving speed data are recorded using a Garmin GPS set up on the roof of the vehicle. Ambient temperature, pressure and relative humidity are monitored at $1 \mathrm{~s}$ time resolution with a meteorological probe (model Testo) installed on the roof of the vehicle. Additionally, an action camera is sometimes set up on the roof to record pictures of the sky, useful for posterior data analysis. A router with an external antenna is used to connect the mobile system to the Internet using a SIM card with $3 \mathrm{G}$ connection. Data acquired during the mobile measurements is further transferred to laboratory-based server for routine processing. An online platform to visualise measurements in real-time is under development.

\subsection{Micropulse lidar}

The lidar included in the MAMS is the CE370 microlidar (Pelon et al., 2008) designed to monitor aerosols and clouds in the troposphere, typically up to $15 \mathrm{~km}$ with a vertical resolution of $15 \mathrm{~m}$. Maximum ranges between 15 and $20 \mathrm{~km}$ can be reached for moderate aerosol loadings. It is a one-channel elastic backscattering lidar operating at $532 \mathrm{~nm}$ with $20 \mu \mathrm{J}$ pulse energy and is developed and commercialised by CIMEL Electronique (http://www.cimel.fr/, last access: 30 March 2018). The instrument's design consists of a shared transmitter-receiver telescope (mono-axis system) connected to the control and acquisition unit through a $10 \mathrm{~m}$ optical fiber. The advantage of the $10 \mathrm{~m}$ optical fiber is that 
it allows deploying the lidar outside of the vehicle for static angular measurements for example. The lidar is autonomous, lightweight and compact, it fulfills eye-safety standards and requires no special authorisation for its operation. These features make it suitable for a mobile system and for continuous, non-supervised operation. The CE370 micro-lidar emits laser pulses, at a $4.7 \mathrm{kHz}$ repetition rate, which can be accumulated over $30 \mathrm{~s}$ or $1 \mathrm{~min}$. For a typical vehicle speed of $110 \mathrm{~km} \mathrm{~h}^{-1}$ this corresponds to a spatial horizontal resolution of approximately 900 and $1800 \mathrm{~m}$ respectively. The lidar control and acquisition unit, enclosing the optical and electronic components, is installed on vibration isolators to minimise shocks while the vehicle is moving. The lidar transmitter-receiver telescope is fixed to the van's floor with a mechanical support, in order to ensure stability during movement. Furthermore, the shared telescope design eliminates any optical misalignment of the emission and reception channels. Also, an inclinometer is attached to the optical head to correct for the platform inclination when driving on steep slopes or for the case when static angular measurements are performed. For the mobile measurements, lidar sounding is performed only in the zenith direction. A second lidar (model CE376 GPNP, CIMEL Electronique) with three acquisition channels, two at $532 \mathrm{~nm}$ (elastic and perpendicularly polarised backscattering) and one at $808 \mathrm{~nm}$ (elastic backscattering), is planned to be integrated in the mobile system's payload after testing and validation with fixed observations.

\subsubsection{Lidar data pre-processing and quality assurance aspects}

In order to obtain the total attenuated backscatter from lidar signals several instrumental corrections are applied: nonlinearity of the detector, afterpulse correction, background sky radiance, overlap and range correction. These have been previously described in Mortier et al. (2013). However, improvements at an instrumental level have been carried on, reducing the blind zone (caused by the afterpulse phenomenon) to $z_{\min }=180 \mathrm{~m}$ for vertical sampling. The afterpulse signal is measured at the beginning of each mobile measurement and subtracted from the total received backscatter signal. Micropulse lidar is a unique, compact system that can be easily deployed in remote locations or integrated on mobile platforms. The system's design causes the full overlap to be reached at ranges between 4-6 km (Berkoff et al., 2003; Campbell et al., 2002). Thus, in order to quantitatively exploit the lidar signals, the overlap factor correction must be very properly assessed and applied.

In our study, the overlap factor has been determined using three methods: (i) the slope method (Kunz and de Leeuw, 1993) using horizontal profiles when the lower atmospheric layers can be considered homogeneous, (ii) the slope method using vertical profiles in fixed location under fair weather conditions with low aerosol loading and (iii) taking the ratio of CE370 micro-lidar signals to another calibrated lidar,

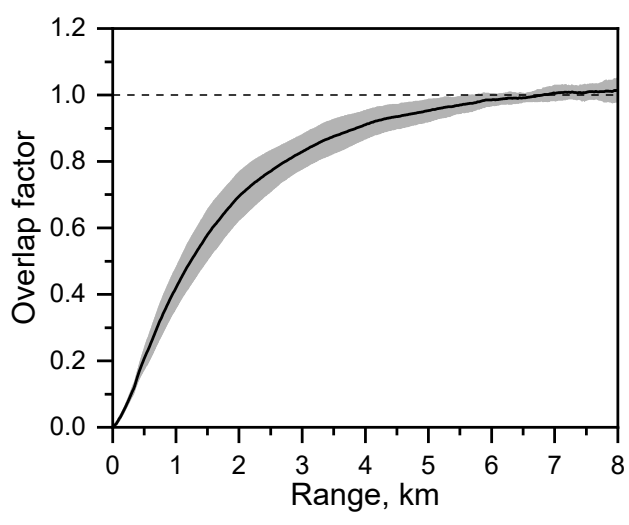

Figure 2. Overlap factor of the CIMEL CE370 lidar on-board the vehicle vs. distance. The combined standard deviation over the three methods used to assess the overlap function correction is represented by the light grey shaded area.

LILAS (Bovchaliuk et al., 2016; Veselovskii et al., 2016), integrated in EARLINET since 2015. Figure 2 shows the average overlap factor assessed using the three methods and its standard deviation as a function of range. The different sources of uncertainty of the overlap functions determined with each method are supposed to be independent so that the total uncertainty is computed by taking the square root of the quadratic sum of each overlap function uncertainty. The overlap correction factor is smaller than 0.1 below $0.3 \mathrm{~km}$, and it reaches unity around $6.8 \mathrm{~km}$. The coefficient of variation of the overlap correction is less than $10 \%$ above $2 \mathrm{~km}$. Below $2 \mathrm{~km}$ it increases by as much as $25 \%$, reaching the maximum at $0.18 \mathrm{~km}$ (minimum altitude considered for exploitable physical signal). Therefore, an uncertainty on the overlap function of $10 \%$ above $2 \mathrm{~km}$ increasing to the surface to about $25 \%$ at $0.18 \mathrm{~km}$ will be considered throughout this study. The overlap correction has been checked using stationary observations in the period 2016-2017 after different mobile campaigns. Considering measurements over a long time period allows checking the overlap correction's stability. By using different methods and different lidar measurements over time, one includes both the systematic and random errors that could impact the overlap factor correction. This explains the high variability and means that all types of possible errors are taken into account. The mean overlap factor assessed using the three methods has been used for processing the lidar signals in this work. The uncertainty on the overlap factor correction has been propagated onto the derived aerosol properties.

After all instrumental corrections are applied, the background, overlap and range-corrected lidar signals are checked according to Rayleigh-fit criteria used in EARLINET lidar quality assurance procedures (Freudenthaler et al., 2018). The relative deviations from the calculated Rayleigh signal fall below $5 \%$ between 5 and $13 \mathrm{~km}$. Between 13 and $16 \mathrm{~km}$ the relative deviations reach $10 \%$, which 
is the maximum acceptable limit. This means that vertical sounding up to $16 \mathrm{~km}$ can be reached with the CE370 microlidar at nighttime and under low aerosol loadings (AOD of 0.06 at $532 \mathrm{~nm}$ ).

It should be noted that the same model of micro-lidar (CE370) has been used for routine continuous aerosol monitoring over Lille, France and M'Bour, Senegal since 2006 and aerosol studies using micro-pulse lidar data are presented in several works (Léon et al., 2009; Mortier, 2013; Mortier et al., 2013, 2016).

\subsubsection{Comparison with reference lidar in EARLINET}

The performance of CIMEL CE370 micro-pulse lidar has been assessed by comparison with a multi-wavelength Raman lidar, IPRAL (Bravo-Aranda et al., 2016) operating at SIRTA (Site Instrumental de Recherche par Télédétection Atmosphérique; Haeffelin et al., 2005), Palaiseau, France $\left(48.7^{\circ} \mathrm{N}, 2.2^{\circ} \mathrm{E} ; 156 \mathrm{ma}\right.$ a.s.l.). The IPRAL lidar system is part of EARLINET and undergoes the network's quality assurance procedures. The most interesting feature of IPRAL for this study is its newly integrated near-field telescope, which gives access to backscattering in the low altitudes of the atmosphere down to $300 \mathrm{~m}$. The combined signals from the two telescopes (near-field and far-field) are used in this work and compared against the signals of the mobile CE370 micro-lidar. The signals from IPRAL are adjusted to a common vertical resolution of $15 \mathrm{~m}$ and no vertical smoothing is applied to any lidar profiles. Night-time measurements on 28 August 2017 at Palaiseau, France are considered for comparison and range corrected signals (RCS) are averaged over 30 min between 23:15 and 23:45 UTC and normalized over a vertical range between $5.6 \mathrm{~km}$ and $7.6 \mathrm{kma.g} .1$., where the aerosol content is considered negligible. The comparison of normalized RCS at $532 \mathrm{~nm}$ from IPRAL and CE370 lidar, along with the molecular profile computed from radiosounding data at Trappes $\left(48.76^{\circ} \mathrm{N}, 2.00^{\circ} \mathrm{E} ; 168 \mathrm{~m}\right.$ a.s.l. $)$ at 00:00 UTC, 29 August 2017, are shown in Fig. 3. The standard deviation of CE370 lidar RCS represented in Fig. 3 as light green shaded area is the uncertainty on the overlap function.

A multi-layer situation was observed at Palaiseau at this time interval, which was an ideal case study for comparing the performance of the two lidar systems. The profiles show a first aerosol layer from the ground up to $1 \mathrm{kma}$ a.g.l. along with a well-separated aerosol layer up to $4.5 \mathrm{~km}$ a.g.l. in the lower troposphere. In the upper troposphere and lower stratosphere cirrus clouds between $10.8 \mathrm{~km}$ and $12.2 \mathrm{~km}$ a.g.l. and an aerosol layer between $17 \mathrm{~km}$ and $20 \mathrm{kma}$.g.l. are observed. The air masses back trajectory analysis (not reported) shows the transport of desert dust in the $2-4.5 \mathrm{~km}$ range and most probably transported biomass burning particles at higher altitudes originating from intense forest fires in Canada (Khaykin et al., 2018).

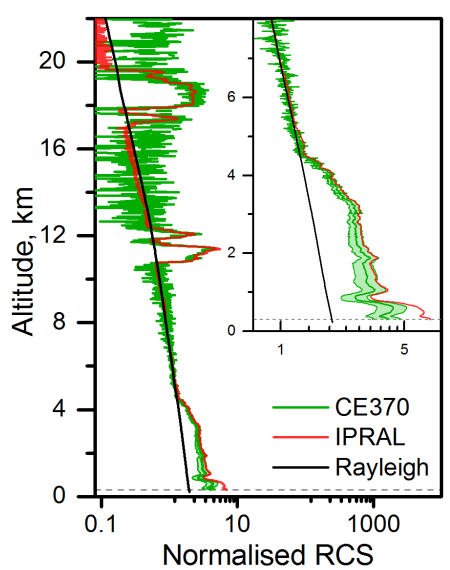

Figure 3. Comparison of the normalized range-corrected signals profiles at $532 \mathrm{~nm}$ recorded by CIMEL CE370 lidar on-board the mobile platform (green) and IPRAL lidar (red) at Palaiseau, France, on 28 August 2017 (23:15-23:45 UTC). The profiles are displayed from $300 \mathrm{~m}$ above (complete overlap altitude of IPRAL system). The Rayleigh profile calculated from radiosonde measurements at Trappes on 29 August 2017, 00:00 UTC is represented by the black line.

The two profiles are remarkably similar, showing very good agreement between the two systems despite the use of the overlap correction for the micropulse lidar data. The largest differences are observed in the overlap correction range of the CE370 lidar but the expected amplitudes of the signals fall within the overlap uncertainty, which means that our overlap correction is reasonable down to $0.6 \mathrm{~km}$. The highest fractional differences between IPRAL and CE370 values of RCS are under $15 \%$ above $2.5 \mathrm{~km}$ and reach $70 \%$ at $0.18 \mathrm{~km}$ altitude (minimum altitude considered for CE370 lidar). The lowest fractional differences are $<5 \%$ above $0.84 \mathrm{~km}$ and up to $50 \%$ at $0.18 \mathrm{~km}$. A good agreement between the two systems is observed with discrepancies that are within the CE370 lidar RCS uncertainty. For higher altitudes in the atmosphere, although the CE370 lidar's signalto-noise ratio above $12 \mathrm{~km}$ is significantly lower compared to IPRAL system, the micropulse lidar is able to detect the aerosol layer in the UTLS (Upper Troposphere Lower Stratosphere) due to the strong backscattering signal of the layers. Applying noise filtering significantly improves the SNR and implies that backscatter signals from far range could be exploitable in such rare situations.

This lidar comparison example is part of an intercomparison campaign that involved both research and micropulse lidars in ACTRIS-FR and METEO-FRANCE networks. This case study shows one side application of the mobile system within checking the uniformity of lidar measurements at different sites and the validation of micro-lidar measurements. 


\subsubsection{Aerosol extinction coefficient profiles and effective extinction-to-backscatter ratio}

The lidar backscattering signals contain information on atmospheric scattering and extinction processes. After all corrections detailed in Sect. 2.2.1 are applied on lidar signals, the lidar equation can be written as

$$
\begin{aligned}
& S(z)=\left(\beta_{\text {aer }}(z)+\beta_{\text {mol }}(z)\right) \\
& \quad \exp \left\{-2 \int_{z_{\text {min }}}^{z}\left(\sigma_{\text {aer }}\left(z^{\prime}\right)+\sigma_{\text {mol }}\left(z^{\prime}\right)\right) \mathrm{d} z^{\prime}\right\},
\end{aligned}
$$

where $S(z)$ is the attenuated backscatter, that is, the lidar background, range, and overlap corrected, calibrated and energy normalized lidar signal. $\beta(z)$ and $\sigma(z)$ are the range dependant volume backscattering and extinction coefficients and the subscripts "aer" and "mol" refer to the contribution of aerosols and molecules, respectively. The lidar equation (Eq. 1) is an undetermined equation, with two unknown variables ( $\beta_{\text {aer }}$ and $\left.\sigma_{\text {aer }}\right)$, so a relationship between the two variables is needed. The aerosol extinction-to-backscatter ratio or lidar ratio (LR) is introduced,

$\operatorname{LR}_{\mathrm{aer}}(z)=\frac{\sigma_{\mathrm{aer}}(z)}{\beta_{\mathrm{aer}}(z)}$,

which depends on the size distribution, wavelength, shape and composition of aerosols

$\mathrm{LR}_{\mathrm{aer}}=\frac{4 \pi}{\varpi_{0} P(\pi)}$,

where $\varpi_{0}$ is the single scattering albedo and $P(\pi)$ is the phase function at scattering angle $180^{\circ}$.

The molecular extinction-to-backscatter ratio is constant, $\mathrm{LR}_{\mathrm{mol}}=8 \pi / 3 \mathrm{sr}$ and $\mathrm{LR}_{\mathrm{aer}}$ must be assumed vertically constant in order to simplify the equation. The methodology to invert lidar signals is similar to that described by Leon et al. (2009) and is based on the Klett (1981) and Fernald (1984) solution to the inverse problem.

$$
\begin{aligned}
& \beta_{\text {aer }}(z)+\beta_{\text {mol }}(z)= \\
& \frac{S(z) \exp \left\{-2 \int_{z_{\text {ref }}}^{z}\left[\operatorname{LR}_{\text {aer }}(z)-\mathrm{LR}_{\text {mol }}\right] \beta_{\text {mol }}(z) \mathrm{d} z\right\}}{\frac{S\left(z_{\text {ref }}\right)}{\beta_{\text {aer }}\left(z_{\mathrm{ref}}\right)+\beta_{\mathrm{mol}}\left(z_{\mathrm{ref}}\right)}-2 \int_{z_{\mathrm{ref}}}^{z} \mathrm{LR}_{\mathrm{aer}}\left(z^{\prime}\right) S\left(z^{\prime}\right)} \\
& \exp \left\{-2 \int_{z_{\text {ref }}} z^{\prime}\left[\mathrm{LR}_{\text {aer }}\left(z^{\prime \prime}\right)-\mathrm{LR}_{\mathrm{mol}}\right] \beta_{\mathrm{mol}}\left(z^{\prime \prime}\right) \mathrm{d} z^{\prime \prime}\right\} \mathrm{d} z^{\prime}
\end{aligned}
$$

where LR is the extinction-to-backscatter ratio or lidar ratio; the subscripts "aer" and "mol" refer to aerosol and molecules lidar ratio. $z_{\text {ref }}$ is the reference altitude, where the signal is supposed to come only from molecular scattering.

Height-independent values of lidar ratio and extinction coefficient profiles are retrieved using an iterative inversion method constrained by sun photometer AOD. A dichotomous approach is used on the LR values converging until the difference between lidar and sun photometer AOD at $532 \mathrm{~nm}$ is minimised. The same method applied on micro-lidar observations has been used in previous studies (Chazette, 2003; Chazette et al., 1995; He et al., 2006; Mortier et al., 2013) and proved to be reliable for deriving realistic LR values, that are consistent with calculated LR from AERONET measurements or with a Mie code. In this work mobile lidar profiles were inverted into extinction coefficient profiles using the constraint of coincident AOD at $532 \mathrm{~nm}$ interpolated from PLASMA measurements.

\subsubsection{Mass concentration profiles}

From extinction coefficient profiles, mass concentration can be derived if assumptions on the atmospheric aerosols are imposed. The profiles of mass concentration are calculated using

$$
M(z)=\frac{4}{3} \sigma_{\mathrm{aer}}(z) \int_{r_{\min }}^{r_{\max }} \frac{\rho(r) \cdot r^{3} \cdot n_{1}(r)}{\int_{r_{\min }}^{r_{\max }} Q_{\mathrm{ext}}(\mathrm{m}, r, \lambda) \cdot n_{1}(r) \cdot r^{2} \mathrm{~d} r} \mathrm{~d} r,
$$

where $r$ is the particle radius, $n_{1}(r)$ is the normalized volume size distribution, $Q_{\text {ext }}$ is the extinction efficiency and $\rho$ is the particle density. The full description of the methodology can be found in Mortier et al. (2013), where it was applied for volcanic ash mass concentration calculations. The method requires knowledge of aerosol size distribution and refractive index and $Q_{\text {ext }}$ is computed using Mie theory. Climatological values for different aerosol types are considered for particle density $(\rho)$. Practically, the sun-photometer-derived size distribution is used, when possible, in order to construct an adequate aerosol model for the atmospheric situation. In this work, the described method to derive aerosol mass concentration from lidar measurements has been applied to mobile observations. The parameters chosen for the calculations will be described for the considered case study in Sect. 3.1.

\subsubsection{Uncertainties}

The most important source of uncertainty on lidar profiles is the uncertainty on the overlap function, especially at lower altitude levels where the incomplete overlap affects the measurements. Applying a wrong overlap correction can lead to an underestimation or overestimation of the attenuated backscatter signals and consequently of the derived variables such as extinction coefficient and mass concentration in the near-field range. Since most of aerosols are located near the surface and up to 1-2 or up to 4-5 km in case of transported aerosols, the problem of incomplete overlap must be solved in order to quantitatively analyse aerosol properties within the first $5 \mathrm{~km}$. An uncertainty of $10 \%$ above $2 \mathrm{~km}$, increasing to $25 \%$ at ground level, was assessed for the overlap correction factor used for our lidar data (Sect. 2.2.1). Additional uncertainties on lidar measurements are the statistical fluctuations of the measured signal, the detector dead-time, the fluctuations in laser energy and the afterpulse correction. Ac- 
cording to Welton and Campbell (2002), the contribution of these corrections is either negligible or less then $5 \%$.

The main sources of uncertainties in the retrieval of extinction coefficient come from the unknown lidar ratio vertical variation, the uncertainty on the lidar signal at the reference altitude, the uncertainty on the overlap function and the missing signal below $z_{\min } \approx 180 \mathrm{~m}$. The molecular model can also induce a relative uncertainty of $5 \%$ according to Chazette et al. (1995). In our study we use the radiosounding data from the closest site when possible, trying to reduce the uncertainties related to the molecular profile. If the layers in the atmosphere are not well-mixed, the assumption of a constant lidar ratio will lead to a bias in the retrieval of extinction coefficient profiles. Nonetheless, we constrain the retrievals with the integrated aerosol extinction (AOD), which improves the reliability of retrieved LR values, compared to the case when a LR is imposed. In the absence of direct measurements of LR vertical variation, column-averaged LR is the closest estimate that can be achieved. The overall error in the aerosol extinction coefficient and lidar ratio is not easy to be precisely computed, so in this study we estimate errors to be in the range of $15-25 \%$, with maximum uncertainty at $z_{\min } \approx 180 \mathrm{~m}$.

As we apply the same methodology as Mortier et al. (2013) to derive the mass concentration profiles for mobile measurements, the same uncertainties have been considered here. Considering an uncertainty of $15-25 \%$ on the extinction coefficient along with the uncertainty on the particle size distribution, refractive index and density, a total average uncertainty of $35-40 \%$ is expected on the mass concentration when considering independent errors.

\subsection{PLASMA sun photometer}

The sun-tracking-photometer PLASMA (Photomètre Léger Aéroporté pour la Surveillance des Masses d'Air), developed by Laboratoire d'Optique Atmospherique (LOA), is set up on the roof of the mobile system for continuous measurements of direct spectral solar radiation. Spectral extinction Aerosol Optical Depths (AOD) are derived from PLASMA measurements. The sun photometer has nine channels at similar spectral range typical for standardised network instruments: $0.339,0.379,0.440,0.500,0.674,0.870,1.019,1.643$ and $0.94 \mu \mathrm{m}$ for the atmospheric precipitable water vapour content. The single-band filters inserted in the optical path are distributed into two motor-driven filter wheels, one for the visible and near-infrared wavelengths and one for the infrared short-wavelengths. The second wheel contains only the $1.643 \mu \mathrm{m}$ channel so it does not turn for the current configuration, but more filters can be added. The full angle field of view (FOV) of the two collimators is $1.5^{\circ}$, which is comparable to the $1.2^{\circ} \mathrm{FOV}$ of CIMEL photometers, limiting sensitivity to atmospheric scattering. PLASMA can move in elevation $\left(0-88^{\circ}\right)$ and azimuth $\left(0-360^{\circ}\right)$ and can rotate in azimuth thanks to a ring power connector, which makes it suitable for mobile applications. A GPS system delivers geographical coordinates used to determine the position of the Sun. The Sun tracking is achieved with the use a fourquadrant detector and a compass giving the heading, pitch and roll of the mobile platform. A more detailed description of the instrument and application to airborne measurements is presented by Karol et al. (2013). PLASMA sun photometer has been also used for airborne measurements up to $12 \mathrm{~km}$ on the French Falcon 20 aircraft during the AEROCLO-SA field campaign over the South Atlantic Ocean as well as during the SHADOW field campaign in M'Bour, Senegal, on-board an ultralight (ULM) aircraft. The acquisition time for a complete sequence of direct-sun radiance measurements for all filters is approximately $1.9 \mathrm{~s}$. As data are filtered for clouds and other obstacles encountered in the line of sight of the sun photometer during motion (trees, buildings, bridges etc.), the temporal sampling is decreased to approximately $10 \mathrm{~s}$. For a typical vehicle speed of $110 \mathrm{~km} \mathrm{~h}^{-1}$ this corresponds to a spatial horizontal resolution of approximately $300 \mathrm{~m}$.

\subsubsection{Sun photometer pre-processing and data quality}

PLASMA sun photometer data are included in the AERONET database (instrument \#650) and the instrument is calibrated by Service National d'Observation PHOTONS, French branch of AERONET, using Langley method at Izaña Observatory $\left(28.3^{\circ} \mathrm{N}, 16.5^{\circ} \mathrm{W} ; 2400 \mathrm{~m}\right.$ a.s.l. $)$ following the AERONET calibration protocol for the AERONET reference master instrument. The PLASMA sun photometer is intercalibrated regularly against a CIMEL CE318 master sun photometer from PHOTONS network at the Carpentras site $\left(44.1^{\circ} \mathrm{N}, 5.1^{\circ} \mathrm{E} ; 100 \mathrm{ma}\right.$ a.s.1.). This allows checking the stability of the instrument as the characteristics may change over time. Figure 4 presents the comparison of spectral AOD from PLASMA and CIMEL sun photometers coincident measurements at Carpentras site, on 12 June 2017. The comparison with a master instrument shows excellent agreement between the two instruments with RMS AOD differences better than 0.005 for all channels. The sun photometer measurements contaminated by obstacles along the transect such as clouds, buildings, trees, bridges, etc., are filtered using the triplet stability criterion described by Smirnov et al. (2000). The filtering is applied on the recorded digital signals and consists in applying a threshold of 1 to $3 \%$ maximum difference between three consecutive measurements within a defined time window (from 10 to $30 \mathrm{~s}$ for stationary measurements). The threshold value relates to the expected AOD variability in a stable atmosphere within the defined time window and is chosen by the user at the time of processing the data. If the condition is not met at any wavelength, the measurements at all wavelengths are eliminated from further processing. Filtered measurements are then submitted manually to AERONET processing system to derive spectral AOD. However, this method takes some time, up to 1 day, to get the calibrated AOD. Therefore, the internal PHO- 


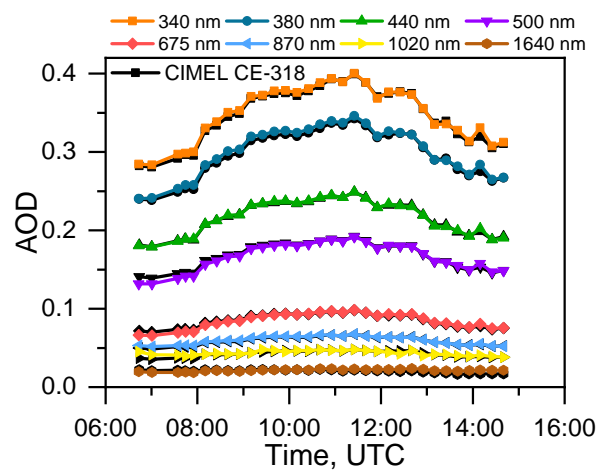

Figure 4. Comparison of the spectral extinction AOD from PLASMA (coloured lines) and CIMEL CE-318 (black lines) sun photometer measurements on 12 June 2017 at Carpentras, France.

TONS AOD computation processing has been considered for campaigns to produce real time AOD. The desktop-based acquisition software shows the AOD not calibrated in real time, useful for checking PLASMA measurements along the road. This monitoring will be improved in order to produce AOD level 1.5 data (cloud screened) in the future STrAP (Système de Traitement des AOD de Plasma) web-based processing system. This will allow the visualisation of real-time calibrated PLASMA AOD.

\subsubsection{Total column volume size distribution}

We use the recently developed GRASP (Generalized Retrieval of Aerosol and Surface Properties) (Dubovik et al., 2014) algorithm and software (more information at http: //www.grasp-open.com/, last access: 30 March 2018) to derive total column aerosol volume size distribution from spectral direct sun photometer measurements. This particular application is called GRASP-AOD and has been described in detail by Torres et al. (2017). The algorithm is based on multi-term least square method; the retrievals start from a priori constraints on actual values and are performed until the residuals are minimised. Aerosols are modelled as a mixture of spherical and non-spherical fractions and the inversion requires an assumption on the refractive index, real part and imaginary part, as well as on the sphere fraction. Six parameters describing the bimodal lognormal size distribution are retrieved, median radius, volume concentration and standard deviation for both fine and coarse mode, as well as secondary aerosol properties such as effective radius, total concentration and fine mode AOD at $500 \mathrm{~nm}$. In this work we show the application of GRASP-AOD inversion to the onroad PLASMA sun photometer measurements. The uniqueness of the algorithm lies in the fact that it does not need coincident sky radiance measurements and it can be used for applications such as mobile sun photometer measurements to determine the spatial variability of total column aerosol size distribution, under certain assumptions and known limitations.

\subsubsection{Uncertainties}

The uncertainty on AOD from PLASMA sun photometer comes from the uncertainty in the calibration transfer from a standard sun photometer. The uncertainty on PLASMA AOD in the visible and NIR is $2 \%$ compared to $1 \%$ for a standard CIMEL sun photometer and $3 \%$ compared to $2 \%$ in the UV.

Regarding the retrieved aerosol total column size distribution, the uncertainty on the fine mode volume median radius $\left(r_{\mathrm{Vf}}\right)$ and volume concentration $\left(C_{\mathrm{Vf}}\right)$ is between $5 \%$ for the fine-mode predominant cases and $10 \%$ for the coarse-mode predominant cases. The uncertainty on the retrieved coarse mode volume median radius $\left(r_{\mathrm{Vc}}\right)$ and volume concentration $\left(C_{\mathrm{Vc}_{\mathrm{c}}}\right)$ is larger than $10 \%$ for the fine-mode predominant cases. For cases with coarse-mode predominance, the uncertainty is $10 \%$ for $r_{\mathrm{Vc}}$ and around $20 \%$ for $C_{\mathrm{Vc}}$, as shown by Torres et al. (2017). The characterisation of fine-mode is quite accurate, even though reliable a priori information on refractive index is needed. The characterisation of the coarse mode is more difficult due to lack of information in this spectral range, but can be improved using moderate a priori information on coarse-mode parameters (for example, from near almucantar inversions).

\subsection{Aerosol spectrometer}

A portable aerosol spectrometer (model Mini-WRAS 1371, Grimm Aerosol Technik) is integrated in the MAMS payload for real-time measurements of airborne particle size and mass distribution. Mass concentrations for the $\mathrm{PM}_{1}, \mathrm{PM}_{2.5}$ and $\mathrm{PM}_{10}$ size fractions are determined based on optical size distribution measurements and assuming a density of $1.7 \mathrm{~g} \mathrm{~cm}^{-3}$, typical value for urban particles. The instrument classifies particles by their electrical mobility diameter and optical diameter in 40 size-bins, from 0.01 to $35 \mu \mathrm{m}$ every minute with a flow rate of $1.2 \mathrm{~L} \mathrm{~min}^{-1}$. Ultrafine and fine particles in the $0.01-0.193 \mu \mathrm{m}$ diameter range are measured with the electrical mobility spectrometer while fine and coarse particles in the $0.253-35 \mu \mathrm{m}$ diameter range are measured with the optical particle counter. In order to conduct accurate aerosol measurements while the vehicle is in motion, an isokinetic stainless-steel sampling probe (model 1.152, Grimm Aerosol Technik) suitable for air velocities up to $25 \mathrm{~m} \mathrm{~s}^{-1}$ is set up on the roof of the car at a height of $50 \mathrm{~cm}$ above the car's roof ( $2.37 \mathrm{~m}$ above ground) in the forwards direction. This setup prevents contamination by the car's own exhaust situated at about $30 \mathrm{~cm}$ above ground.

Optical particle counters (OPC) similar to mini-WRAS aerosol spectrometer have been used for mobile applications such as aircraft, car and underground station measurements (Bush et al., 2015; Cheng and Lin, 2010; Weber et al., 2012). Grimm and Eatough (2009) have shown that the 
$\mathrm{PM}_{x}$ mass concentrations obtained from the conversion of size distribution to mass distribution are in good agreement with FDMS measurements, equivalent to gravimetric measurements. Comparison of the GRIMM mini-WRAS particle counter with a conventional TEOM FDMS monitor from an air quality station situated nearby, around $5 \mathrm{~km}$ distance from our laboratory, shows very good agreement between the two instruments, despite the different methods and different locations. This demonstrates the reliability of the derived $\mathrm{PM}_{x}$ mass concentrations presented further in our study.

\section{Results}

Two case studies are presented in this section, aiming to give examples of the products that the algorithms can provide and also to illustrate the applications of an instrumented mobile system. Section 3.1 focuses on remote sensing measurements performed in the north of France on 26 August 2016, along the transect Lille-Dunkerque. Comparisons with satellite AOD data from Moderate Resolution Imaging Spectroradiometer (MODIS) Aqua daily product MYD04 and with simulations from Dust Regional Atmospheric Model (BSC-DREAM8b) are performed and presented. Section 3.2 presents in situ measurements performed along the route of Lille-Paris on 28 August 2017. Comparison between onroad particle counter-derived $\mathrm{PM}_{10}$ and ATMO Hauts-deFrance and AIRPARIF PM $_{10}$ measurements and modelled $\mathrm{PM}_{10}$ concentrations are conducted and included in this section.

\subsection{Remote sensing mobile measurements in northern France}

\subsubsection{Observation strategy and meteorological conditions}

The MAMS mobile exploratory platform was deployed in northern France in the spring and summer periods of 20152017, periods marked by higher occurrence of pollution events (Unga, 2017). During the same periods, long-range transport of aerosols over northern France region is quite frequently observed by our continuous measurements. The work of Mortier (2013) illustrates variability of aerosol events over Lille during 2006-2012 period.

We present mobile measurements performed on $26 \mathrm{Au}-$ gust 2016 on the route between Lille $\left(50.61^{\circ} \mathrm{N}, 3.14^{\circ} \mathrm{E}\right)$ and Dunkerque $\left(51.03^{\circ} \mathrm{N}, 2.37^{\circ} \mathrm{E}\right)$, situated $80 \mathrm{~km}$ northwest of Lille. Mobile measurements were performed between 12:00 and 13:07 UTC (local time is UTC +02: 00) along the Lille-Dunkerque route and between 14:20 and 15:52 UTC along Dunkerque-Lille route. The mobile measurements were triggered based on chemical transport model forecasts provided by the ESMERALDA platform (http://www.esmeralda-web.fr/, last access: 30 March 2018) and PREV'air system (http://www2.prevair.org/, last access: 30 March 2018) and based on BSC dust forecasts (http://www.bsc.es/ess/bsc-dust-daily-forecast, last access: 30 March 2018). Daily maximum PM $_{10}$ concentrations at ground level exceeding $50 \mu \mathrm{g} \mathrm{m}^{-3}$ were expected for Lille and lower concentrations around $30 \mu \mathrm{g} \mathrm{m}^{-3}$ for Dunkerque. $\mathrm{PM}_{10}$ concentrations at ground level measured by air quality stations in Lille exceeded $100 \mu \mathrm{g} \mathrm{m}^{-3}$ at 07:00 local time, which led us to investigate this pollution event. The prediction maps showed that the pollution plume covered the Netherlands, Belgium and northern France regions, with an increase in particulate matter and $\mathrm{NO}_{2}$ concentrations, which are indicators of anthropogenic pollution. Total $\mathrm{NO}_{2}$ from OMI satellite measurements (http://www.temis. nl/airpollution/no2.html, last access: 30 March 2018) indeed showed an increase of concentrations over northern France, Belgium and the Netherlands. The BSC DREAM8b model indicated transport of dust over the coastal region, penetrating inland up to Lille and dust layers between 2 and $5 \mathrm{~km}$, of low concentration, were predicted for Lille. Regarding the meteorological conditions, anticyclonic conditions maintained a dry and sunny weather over the north of France, with near surface temperatures between 26 and $28^{\circ} \mathrm{C}$ at Lille and around $21^{\circ} \mathrm{C}$ at Dunkerque and with low wind speeds in the range of 11 to $13 \mathrm{~km} \mathrm{~h}^{-1}$ from the north-northeast direction.

The main goal of our measurements was to reveal the spatial variability of atmospheric structures and the evolution of the aerosol optical properties (aerosol extinction coefficient) along the route, away from Lille agglomeration. The existence of a major motorway axis between Lille and Dunkerque makes it possible to sample this region easily and quickly.

\subsubsection{Spatial variability of AOD and comparison with MODIS data}

A strong variability was observed between the two end points, Lille and Dunkerque. High AOD values in the range $0.6-0.8$ at $440 \mathrm{~nm}$ were recorded at Lille and surroundings between 11:00 and 12:00 UTC and decreased rapidly to 0.37 when arriving at Dunkerque around 13:07 UTC. The Ångström exponent, between 1.4 and 1.6 at Lille, decreased to 1.2 along the route to Dunkerque. The values recorded at Lille are characteristic for fine particles, typical for urban sites, while the decrease of the Ångström exponent along the road indicates the presence of larger particles. During $1 \mathrm{~h}$ of stationary measurements starting from 13:15 UTC, the AOD levels remained stable around 0.4. On the way back to Lille, AOD and Ångström exponent values increased to 0.75 and 1.6, respectively. AOD at $440 \mathrm{~nm}$ and Ångström exponent from PLASMA measurements were compared with data from closest AERONET sites (Lille and Dunkerque) and a mean absolute difference of 0.04 was found, proving the reliability of PLASMA measurements. One must take into account that, for this comparison, the closest measurements (in space and time) were considered and that they are not taken at the exact same location as AERONET sites. 

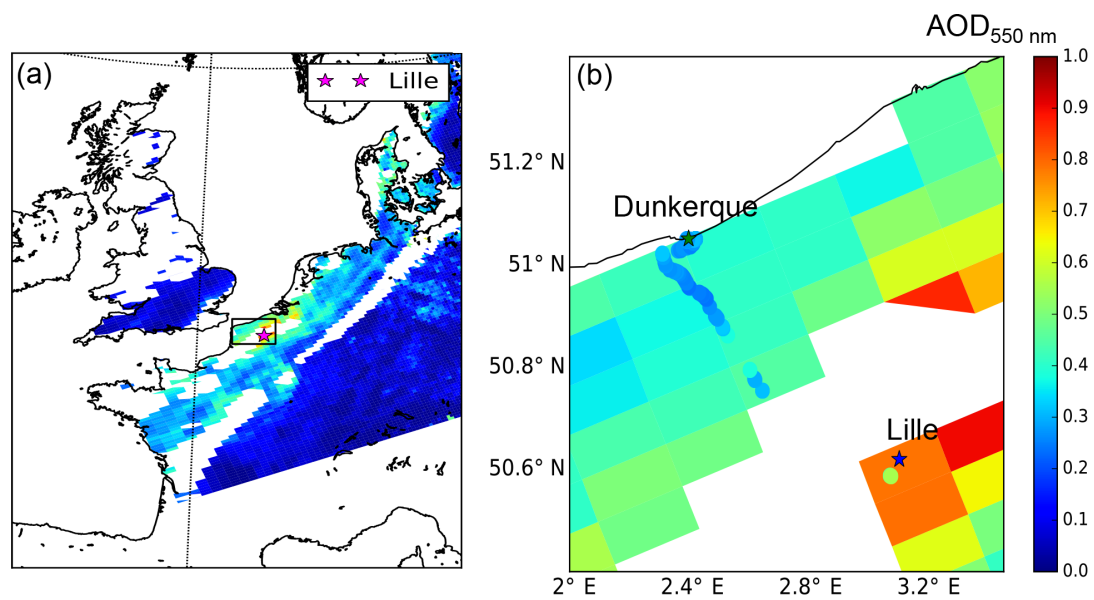

Figure 5. Spatial distribution of (a) MODIS Aqua AOD $(550 \mathrm{~nm})$ daily product MYD04 $10 \mathrm{~km}$; (b) AOD (550 nm) from PLASMA sun photometer on-road measurements along the Lille-Dunkerque transect on 26 August 2016 are overlapped on MYD04 AOD product.

As an example of the applications of the mobile system, MODIS AOD data has been evaluated by comparison with ground mobile sun photometer measurements. We used the MODIS deep blue (DB) product at $10 \mathrm{~km}$ over land (Levy et al., 2013) for the comparisons. MODIS AOD product with higher resolution $(3 \mathrm{~km})$ would have been preferred to better address pollution gradients, but not enough pixels coincident with our mobile transect were available for this day. Figure 5 presents satellite AOD retrievals at $550 \mathrm{~nm}$ from MODIS Aqua daily product MYD04 along with AOD at $550 \mathrm{~nm}$ from mobile PLASMA sun photometer measurements. PLASMA data were spectrally interpolated to $550 \mathrm{~nm}$ using the standard Ångström exponent method. The overpass of the Aqua satellite over the region is at 12:05 UTC, so we chose the route Lille-Dunkerque as representative for our analysis, as mobile measurements started around 12:00 UTC. The mean sun photometer AOD was obtained by averaging AOD data that fell in each MODIS pixels. Five sets of PLASMAMODIS AOD were considered for comparison within the sampling box.

Having a larger spatial coverage, MODIS data shows higher AOD values along the coast and over northern France and Belgium-Netherlands regions, in the range 0.3 and 0.8 , which is consistent with model predictions of the pollution event and of the dust transport. As we can see, PLASMA and MODIS data are in good agreement. MODIS was highly correlated with ground mobile sun photometer with $R^{2}$ of 0.76 , slope of 1.13, intercept of 0.11 and RMSE of 0.17 . These results are consistent with the findings of Wang et al. (2017), $R^{2}$ of 0.76 , slope of 0.9 , intercept of 0.11 and RMSE of 0.17 for Aqua-MODIS AOD at $3 \mathrm{~km}$ (MYD04_3K). The results of comparison are very good considering the uncertainty due to the atmospheric variability imposed by atmospheric motion and different times of MODIS and PLASMA measurements. The lack of AOD data in the same regions for both instruments is also consistent and is due to the presence of scattered clouds at $4 \mathrm{~km}$ altitude, showing that both cloudscreening algorithms are successful.

\subsubsection{Analysis of lidar vertical observations}

Figure 6 shows the lidar range-corrected signals (RCS) recorded along the route Lille-Dunkerque (Fig. 6a) and Dunkerque-Lille (Fig. 6b), respectively. High aerosol backscatter is observed up to $1 \mathrm{~km}$ altitude at Lille, explained by an on-going particle pollution event, decreasing towards the coastal region (Dunkerque). According to the chemistry-transport model predictions, the pollution event impacted Lille city and surroundings within $30 \mathrm{~km}$ distance with predicted $\mathrm{PM}_{10}$ levels exceeding $50 \mu \mathrm{g} \mathrm{m}^{-3}$, while a gradient in $\mathrm{PM}_{10}$ concentrations was expected when moving westward, towards the coast. This is consistent with our lidar observations, showing a decrease in the aerosol backscatter in the first aerosol layer (from surface up to $1 \mathrm{~km}$ ) approximately $30 \mathrm{~km}$ away from Lille and even a stronger decrease when approaching Dunkerque. This gradient was observed with our mobile measurements during the whole day, for both transects. The PBL height decreased from $1 \mathrm{~km}$ at Lille to $0.6 \mathrm{~km}$ at Dunkerque, showing the contrast between continental and coastal sites. Moreover, outside the Lille region, the presence of several aerosol layers up to $5 \mathrm{~km}$ is revealed. These layers are hardly observed over Lille due to the strong backscatter in the lower altitudes, which strongly attenuates the laser beam. Dust aerosol layers between 2 and $5 \mathrm{~km}$ were observed by lidar measurements as confirmed by Dust Regional Atmospheric Model (DREAM, http://www.bsc.es/projects/earthscience/visor/bases_datos/ image_viewer/docs/BSC_DREAM8b_model_description. pdf, last access: 8 August 2018). Lower Ångström exponent along the road and at Dunkerque indicate an increase of the aerosol coarse-mode fraction and the analysis of backward trajectories performed with HYSPLIT (Hybrid Single 


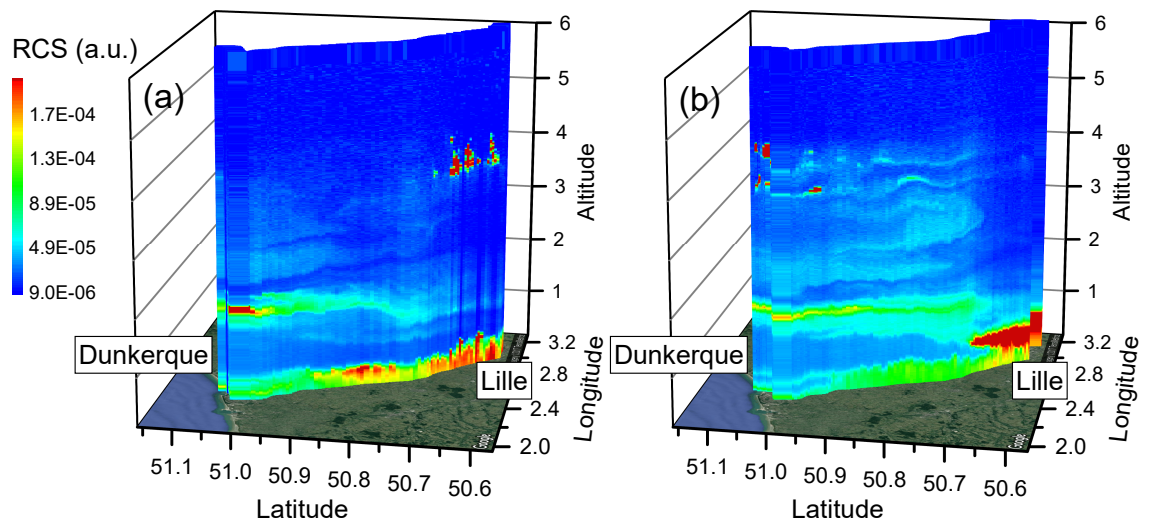

Figure 6. Three-dimensional view on the spatio-temporal variability of the LiDAR range-corrected signals measured along the (a) LilleDunkerque and (b) Dunkerque-Lille transects on 26 August 2016. Observed structures: PBL up to $1 \mathrm{~km}$ altitude, elevated aerosol layers between 2 and $5 \mathrm{~km}$ and scattered clouds at $4 \mathrm{~km}$ near Lille and Dunkerque in red.

Particle Lagrangian Integrated Trajectory) model confirm dust transport over northern France.

\subsubsection{Sun-photometer-derived volume size distribution}

Total column aerosol volume size distributions retrieved with GRASP-AOD are presented in Fig. 7. At the left part of Fig. 7 spectral AOD from PLASMA and AERONET sun photometer measurements at Lille (15:31 UTC) and Dunkerque (13:54 UTC) are shown. The GRASP-AOD inversions and AERONET standard inversions are illustrated in the middle and right part of Fig. 7 for Dunkerque and Lille, respectively. Note that PLASMA measurements are performed at slightly different locations and times, compared to AERONET data. The fine mode volume median radius $\left(r_{\mathrm{Vf}}\right)$ is in the range of 0.18 to $0.16 \mu \mathrm{m}$ for Lille and Dunkerque, respectively, while $r_{\mathrm{Vf}}$ from AERONET standard inversion is 0.18 and $0.20 \mu \mathrm{m}$, respectively. For coarse mode volume median radius $\left(r_{\mathrm{Vc}}\right)$ values of 2.25 and $2.17 \mu \mathrm{m}$ are obtained, while AERONET gives 2.48 and $2.30 \mu \mathrm{m}$ for Lille and Dunkerque, respectively. The concentration values of the fine mode obtained for Dunkerque are $C_{\mathrm{Vf}}=0.04 \mu^{3} \mu \mathrm{m}^{-2}$ (GRASP-AOD) and $C_{\mathrm{Vf}}=0.04 \mu \mathrm{m}^{3} \mu \mathrm{m}^{-2}$ (AERONET) and of the coarse mode are $C_{\mathrm{Vc}}=0.07 \mu \mathrm{m}^{3} \mu \mathrm{m}^{-2}$ (GRASPAOD) and $C_{\mathrm{V}_{\mathrm{c}}}=0.06 \mu \mathrm{m}^{3} \mu \mathrm{m}^{-2}$ (AERONET). For Lille, $C_{\mathrm{Vf}}=0.08 \mu \mathrm{m}^{3} \mu \mathrm{m}^{-2}$ is retrieved with GRASP-AOD compared to $C_{\mathrm{Vf}}=0.12 \mu \mathrm{m}^{3} \mu \mathrm{m}^{-2}$ from AERONET inversion while for coarse mode, $C_{V_{c}}=0.07 \mu \mathrm{m}^{3} \mu \mathrm{m}^{-2}$ from GRASP-AOD and $C_{\mathrm{V}_{\mathrm{c}}}=0.06 \mu \mathrm{m}^{3} \mu \mathrm{m}^{-2}$ from AERONET. We should note that the AERONET inversion for Lille does not pass the Level 2 criteria of Version 3 that requires at least three measurements to be available for scattering angles equal or higher than $80^{\circ}$. This can induce some bias in the retrievals of size distribution.

An a priori refractive index of $1.46-0.003 i$ was used for the inversions, choice made taking into account the closest
AERONET standard inversions and the predominant aerosol types within the atmospheric column. A good consistency between the volume size distribution from AERONET standard inversion and GRASP-AOD inversions is generally observed taking into account the uncertainties discussed in Sect. 3.2.4. Figure 8 illustrates the volume size distribution from GRASP-AOD inversions along Lille-Dunkerque transect (12:18-13:07 UTC). Few sun photometer measurements were possible at the departure time (12:00 UTC) due to the presence of scattered clouds and are not shown, but higher amplitude of fine mode fraction is observed at Lille and close to Lille, decreasing towards Dunkerque. The fine-mode predominant size distributions show that the fine particles pollution episode is localised over Lille region, while the coarse mode contribution comes partly from dust transport. This is a unique illustration of the spatial variability of column size distribution as retrieved with GRASP-AOD from mobile sun photometer measurements.

\subsubsection{Aerosol extinction coefficient profiles and extinction-to-backscatter ratio}

Figure 9 presents the spatio-temporal variability of extinction coefficient profiles along the route Lille-Dunkerque retrieved by applying the Klett inversion algorithm to lidar data constrained by coincident AOD. The upper range for the reference signal is taken between 5 and $5.5 \mathrm{~km}$ where the aerosol contribution is considered negligible. This has been checked against the molecular profile calculated using radiosounding data on 26 August 2016, 12:00 UTC from Trappes $\left(48^{\circ} 45^{\prime} \mathrm{N}\right.$, $\left.2^{\circ} \mathrm{E}\right)$. In this study, the extinction coefficient profile is extrapolated from $z_{\min } \approx 180 \mathrm{~m}$ to the ground level.

The contrast in extinction coefficient between the surroundings of Lille and towards the coastal site is striking. Mean and maximum extinction of 0.13 and $0.33 \mathrm{~km}^{-1}$, respectively, for the first layer up to $0.7 \mathrm{~km}$, are found close to 

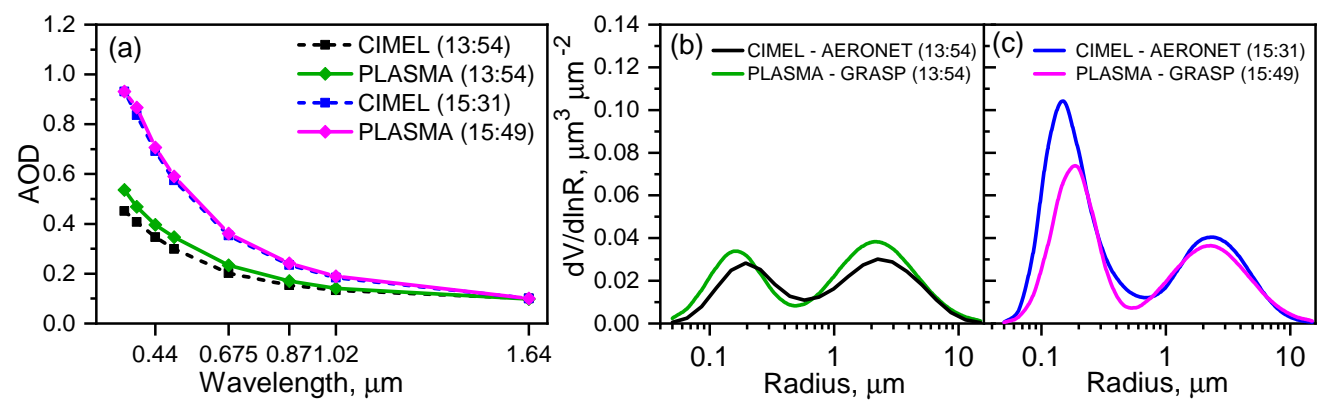

Figure 7. (a) Spectral AOD from PLASMA sun photometer measurements at Dunkerque, on 26 August 2016, 13:54 UTC (green solid line) and Lille, 15:49 UTC (magenta solid line). The closest spectral AOD from Dunkerque and Lille AERONET sites are represented with dashed lines. The corresponding total column aerosol volume size distribution retrieved by GRASP-AOD inversions for (b) Dunkerque and (c) Lille sites. The size distributions from the closest AERONET standard inversion for Dunkerque (13:54) and Lille (15:31) are also represented as reference.

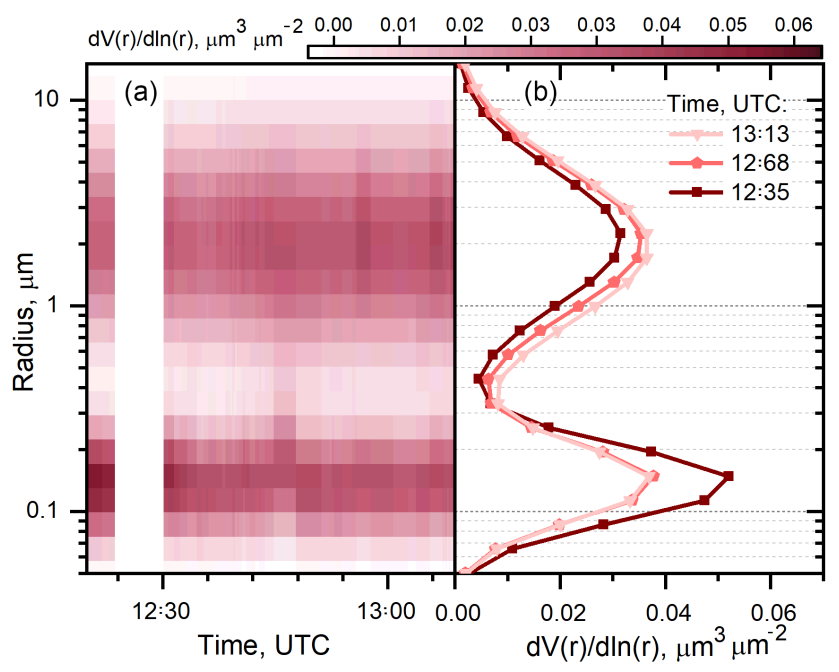

Figure 8. Spatio-temporal variability of total column aerosol volume size distribution retrieved with GRASP-AOD using mobile sun photometer measurements along the Lille-Dunkerque transect on 26 August 2016 (12:18-13:10 UTC).

Lille, while values of 0.05 and $0.14 \mathrm{~km}^{-1}$ for mean and maximum extinction are found along the second half of the road. A second layer is revealed between 1.7 and $2.2 \mathrm{~km}$, with mean and maximum extinction of 0.17 and $0.54 \mathrm{~km}^{-1}$, respectively. The fine layers between 2.5 and $5 \mathrm{~km}$ show lower contribution to the total aerosol loading with mean and maximum extinction of 0.04 and $0.10 \mathrm{~km}^{-1}$, respectively.

The column-integrated lidar ratio (LR) ranges from 35 $( \pm 7)$ to $60( \pm 14) \mathrm{sr}$ and the average value is close to 43 $( \pm 14)$ sr. Higher LR are found close to Lille, between 51 $( \pm 10)$ and $60( \pm 14)$ sr. The LR have been also calculated with a Mie code using the GRASP-AOD derived size distribution and refractive index associated for inversions and the LR values, in the range 40-49 sr, are in good agreement with the lidar-derived LR. The LR retrieved from lidar data have

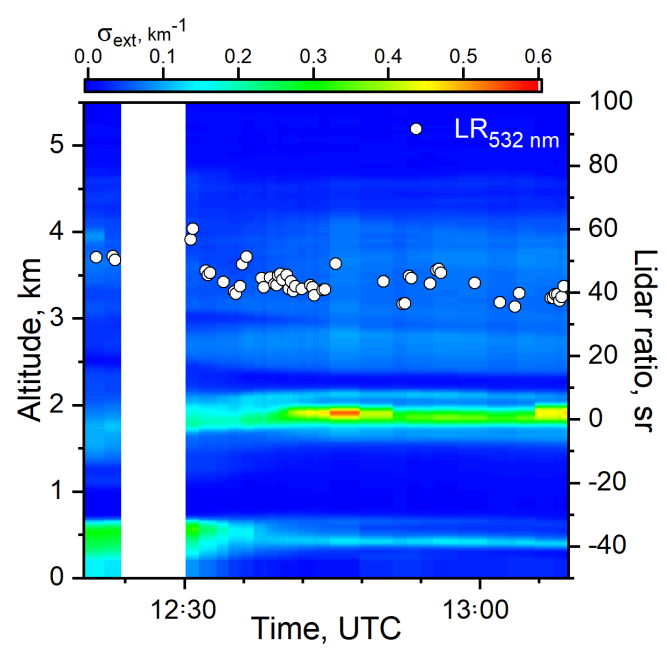

Figure 9. Spatio-temporal variability of extinction coefficient (colour map) and extinction-to-backscatter ratio (white dots) at $532 \mathrm{~nm}$ from on-road mobile measurements along the LilleDunkerque transect on 26 August 2016 (12:18-13:10 UTC).

been also compared to values derived from standard CIMEL sun photometer measurements (Léon et al., 2009) and were found to be on average $20 \%$ lower, which was observed also in our case when comparing our results with LR calculated from AERONET standard inversions. However, the values of LR from standard sun photometer lie within the uncertainty on LR caused by the uncertainty on overlap correction.

The fine dust layers above $2.5 \mathrm{~km}$ have a small contribution to the column effective LR, so the values obtained can be attributed to the aerosol layers below. The values found are characteristic to small, absorbing anthropogenic particles with LR values typically between 50 and $80 \mathrm{sr}$ (Ackermann, 1998). The values of LR are in good agreement with other studies on coastal sites: 32-63 sr in Sagres, Portugal (Ansmann et al., 2001) and $33( \pm 14)$ to $65( \pm 15)$ sr at Dunkerque, France, during sea breeze events (Boyouk et al., 2011). In our 
case, the decrease in LR when approaching Dunkerque also suggests a change from urban aerosol type to a more marine type. A shallow layer at $400 \mathrm{~m}$ causes a strong backscatter, suggesting that this is the marine boundary layer. The height-resolved lidar profiles indicate that the layers of marine and continental particles are well delimited, probably due to a stable stratification of the lowermost layers prohibiting the mixing between different aerosol types. We suppose that particles in the second layer, between 1.7 and $2.2 \mathrm{~km}$, are of different nature than the particles in the layers above, and that they are more absorbing and hygroscopic. This hypothesis is based on stationary observations at Dunkerque that showed possible water uptake by particles in this layer, leading to an increase of the particle size explained by a decrease in Ångström exponent and a rapid increase in the backscatter coefficient. If the relative humidity at this level is close to saturation this leads to a large increase in the aerosol extinction coefficient. However, it is not possible to conclude on this effect without the actual profile of relative humidity. These are only hypotheses that could be clarified with more information on particle size and shape, using a $2 \lambda$ lidar and polarisation channel (CIMEL, model CE376), planned to be integrated in the mobile system's payload.

\subsubsection{Comparison with BSC-DREAM8b at fixed location}

In our study, we evaluate the BSC-DREAM model simulations over Lille by intercomparison with ground-based lidarsun-photometer measurements. Figure 10 shows the comparison between the aerosol extinction coefficient and mass concentration profiles at $532 \mathrm{~nm}$ derived from lidar-sunphotometer mobile measurements near Lille, at 15:30 UTC, and the dust extinction coefficient and concentration profiles at $550 \mathrm{~nm}$ from BSC DREAM8b simulations for Lille, 16:00 UTC. The uncertainty due to the overlap correction is represented with light shaded area. The extinction AOD at $532 \mathrm{~nm}$ for the mean profile in Fig. 10a is 0.53 and the lidar ratio is $66( \pm 14) \mathrm{sr}$, close to the column integrated lidar ratio $(59 \mathrm{sr})$ derived from AERONET standard inversion at Lille, 15:30 UTC.

We first compared the aerosol extinction coefficient at the lowest lidar detectable range $(180 \mathrm{~m})$ with the extinction coefficient at ground level computed at $532 \mathrm{~nm}$ using Mie theory. Aerosol scattering and absorption coefficients can be calculated if the size distribution and refractive index are known and assuming spherical particles. For our Mie calculations we used the size distribution measured at Lille, 15:30 UTC, by an aerosol spectrometer and the refractive index was computed using an indirect method. For the last nephelometer and aethalometer measurements at Lille, 08:00 UTC, aerosol absorption and scattering coefficients were simulated for different refractive indices until the difference between measured and computed scattering and absorption coefficients was minimised. A value of $1.58-0.01 i$ was found for the

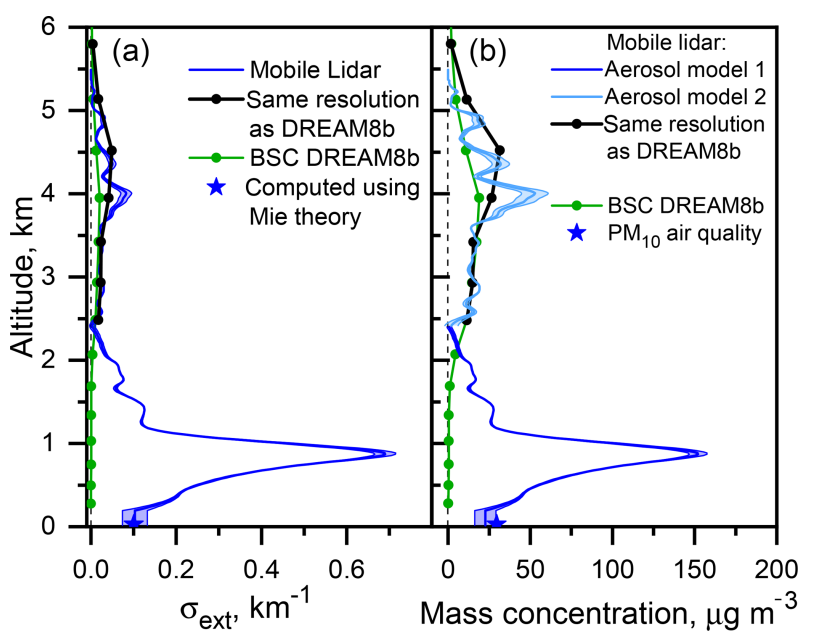

Figure 10. Comparison of (a) extinction coefficient and (b) mass concentration mean profile at Lille, 15:30 UTC from mobile lidar-sun-photometer measurements $(532 \mathrm{~nm})$ (blue) with BSCDREAM8b mean dust extinction and concentration at $550 \mathrm{~nm}$ (green). Data points from mobile measurements in the range 2.5$5 \mathrm{~km}$ are reduced to the model resolution (black) for comparison with the simulated dust profiles.

complex refractive index. This value is within the range of retrieved refractive indices of $1.56-0.01 i$ to $1.58-0.01 i$ found by Levin et al. (2009) for a mixture of organics, soil, sulfates, nitrates and carbon, which are characteristic components in urban environments (Niemi et al., 2006). After finding the refractive index, we apply Mie theory to compute aerosol extinction coefficient at $532 \mathrm{~nm}$. We can see in Fig. 10a an excellent agreement between the calculated extinction coefficient $\left(0.10 \mathrm{~km}^{-1}\right)$ at ground level and the near surface (180 ma.g.1.) lidar-derived extinction coefficient $\left(0.10 \pm 0.03 \mathrm{~km}^{-1}\right)$.

In order to compare our observations to the BSC's DREAM8b dust model simulations, the lidar extinction coefficient profile was reduced to the model's vertical resolution by applying sliding averages around model's height levels. The dust layer is delimited between 2 and $5.8 \mathrm{~km}$ according to both observations and model. The mean lidar-derived extinction is $0.025 \mathrm{~km}^{-1}( \pm 0.015)$, while the model's mean extinction is $0.012 \mathrm{~km}^{-1}( \pm 0.006)$, resulting in a mean bias of -0.01 and a RMSE of 0.02 . For the comparison, it should be kept in mind that the lidar-derived extinction coefficient uncertainties are of the order of 15-25\%. The optical depth of the dust layer is 0.08 at $532 \mathrm{~nm}$ from lidar observations compared to 0.04 at $550 \mathrm{~nm}$ from model simulations. The differences between model and observations can be explained by the limited vertical model resolution compared to the lidar resolution and by the spatial and temporal differences between the observed and modelled profiles considered for the comparison. The contribution of anthropogenic pollution below $2.5 \mathrm{~km}$ explains the differences between model 
and observations, as the model provides extinction coefficient only for dust particles. Mobile observations between Lille and Dunkerque show that the predictions of the dust model is correct, even for low AOD of the dust layers. A strong peak in extinction is observed at $870 \mathrm{~m}$, with value as high as $0.69 \mathrm{~km}^{-1}( \pm 0.02)$. Radiosonde measurements at Trappes at 12:00 UTC (not shown here) show a PBL height of the order of $878 \mathrm{~m}$, marked by a maximum of relative humidity of $73 \%$, which agrees surprisingly well, despite different locations, with the strong increase in extinction coefficient at $870 \mathrm{~m}$ a.g.l. observed from lidar measurements over Lille. Urban aerosols are subject to water uptake (Swietlicki et al., 2008), which leads to changes in aerosol optical properties that could explain the high extinction values at the top of the PBL.

The lidar-derived mass concentration profiles (Fig. 10b) were calculated from the retrieved extinction coefficient and by assuming typical aerosol properties. A first aerosol model, constituted of a fine-mode dominant volume size distribution and a refractive index of 1.58-0.01i, was applied for calculations of mass concentrations up to $2.4 \mathrm{~km}$ altitude, while above $2.4 \mathrm{~km}$, a size distribution with equal contributions of fine and coarse fractions and a complex refractive index of $1.5-0.005 i$ were used. These choices were made based on hypotheses on the aerosol types within the atmospheric column: small, absorbing particles in the first layers up to $2.4 \mathrm{~km}$ and less absorbing, transported dust particles above. The aerosol density values used for the calculations were 1.7 and $2.6 \mathrm{~g} \mathrm{~cm}^{-3}$, relevant for urban and desert dust particles, respectively. A mean lidar-derived mass concentration of $16 \pm 10 \mu \mathrm{g} \mathrm{m}^{-3}$ is obtained for the dust layer above $2.4 \mathrm{~km}$, compared to a mean modelled dust concentration of $11 \pm 6 \mu \mathrm{g} \mathrm{m}^{-3}$, resulting in a mean bias of -5 and a RMSE of 9 . These results show a pretty good agreement in regard to the uncertainties on both observations and model sides. The calculated mass concentration for the urban aerosols below $2.4 \mathrm{~km}$ reaches a maximum of $152 \pm 5 \mu \mathrm{g} \mathrm{m}^{-3}$ at $870 \mathrm{~m}$ and a value of $23 \pm 6 \mu \mathrm{g} \mathrm{m}^{-3}$ at near surface (180 ma.g.1.). The near-surface value is comparable to the closest $\mathrm{PM}_{10}$ from ATMO Hauts-de-France (Lille Fives) air quality measurement, of $30 \mu \mathrm{g} \mathrm{m}^{-3}$ at 15:45 UTC.

\subsubsection{Mass concentration profiles}

Figure 11 presents vertically resolved mass concentration of aerosols retrieved from mobile measurements along LilleDunkerque route (same as in Sect. 4.1.5) using the opticalto-mass relationship defined in Sect. 3.2.3 and the microphysical properties defined in Sect. 4.1.6. We can notice that the concentration in the PBL is lower along the route and at Dunkerque (12:36-13:08 UTC), mean and maximum of 28 and $77 \mu \mathrm{g} \mathrm{m}^{-3}$, respectively, than at Lille, mean and maximum of 77 and $175 \mu \mathrm{g} \mathrm{m}^{-3}$, respectively. Mass concentrations of the layer between 1.7 and $2.2 \mathrm{~km}$ reach a maximum of $287 \mu \mathrm{g} \mathrm{m}^{-3}$ and a mean value of $90 \mu \mathrm{g} \mathrm{m}^{-3}$. Higher con-

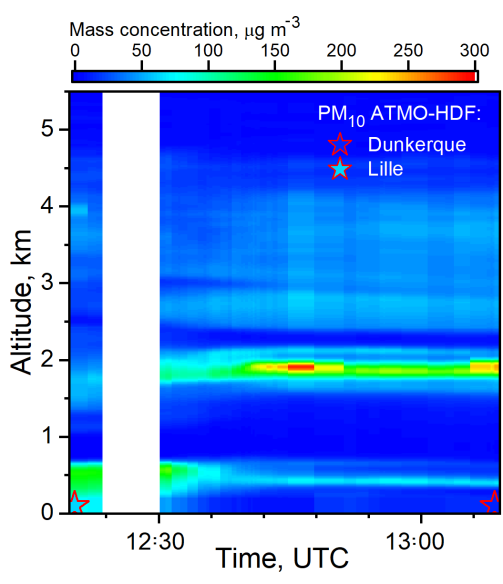

Figure 11. Spatio-temporal variability of lidar-sun-photometerderived mass concentration (colour map) from on-road measurements along Lille-Dunkerque transect on 26 August 2016 (12:18 13:10 UTC). The $\mathrm{PM}_{10}$ mass concentrations from closest measurements from air quality stations along the route are overlapped (colour mapped stars).

centrations in this layer can be explained by an increase in the extinction coefficient. Dust layers aloft $2.5 \mathrm{~km}$ show mass concentration of 26 and $62 \mu \mathrm{g} \mathrm{m}^{-3}$ for mean and maximum, respectively. Finally, we compared the lidar-derived mass concentration at the lowest detectable lidar range, located at $180 \mathrm{~m}$, with $\mathrm{PM}_{10}$ at ground level from two ATMO Hautsde-France air quality stations, at Lille (Fives) and Dunkerque (Malo-les-Bains). The values from ATMO Hauts-de-France correspond to an averaged value over the last $15 \mathrm{~min}$, while closest measurement in time was selected for mobile measurements. At Lille, a value of $58 \mu \mathrm{g} \mathrm{m}^{-3}$ was measured at 12:30 UTC, while the lidar-derived mass concentration at 12:21 UTC, $30 \mathrm{~km}$ from Lille, was $77 \mu \mathrm{g} \mathrm{m}^{-3}$. At Dunkerque, the station recorded a $\mathrm{PM}_{10}$ value of $13 \mu \mathrm{g} \mathrm{m}^{-3}$ at 13:15 UTC compared to $14 \mu \mathrm{g} \mathrm{m}^{-3}$ from lidar-derived mass concentration calculations. Taking into account all the hypotheses on the aerosol microphysical and optical properties and the uncertainty on the measurements, a maximum uncertainty of $40 \%$ has been previously defined. One can notice that in this case the relative difference between the lidar-derived mass concentration and the air quality measurements does not exceed $30 \%$.

\subsection{In situ mobile measurements and comparison with modelled $\mathbf{P M}_{10}$}

In this part we illustrate how the aerosol spectrometer mobile measurements reveal the spatial variability of the particle concentration at the surface level. These measurements are complementary to the ones of lidar because they are carried out at ground level, in the lidar's "blind zone" (from surface to $180 \mathrm{~m}$ a.g.1.). Additionally, it allows the verification of the order of magnitude of the particle mass concentration 
Table 1. Comparison of measured $\mathrm{PM}_{10}$ from air quality stations closest to the investigated route and the corresponding mobile measurements.

\begin{tabular}{|c|c|c|c|c|c|c|}
\hline Air quality (AQ) station & $\begin{array}{l}\text { Station } \\
\text { type }\end{array}$ & $\begin{array}{r}\text { UTC } \\
\text { AQ }\end{array}$ & $\begin{array}{l}\mathrm{PM}_{10} \mathrm{AQ} \\
\left(\mu \mathrm{g} \mathrm{m}^{-3}\right)\end{array}$ & $\begin{array}{r}\text { UTC } \\
\text { mobile }\end{array}$ & $\begin{array}{r}\mathrm{PM}_{10} \text { mobile } \\
\left(\mu \mathrm{g} \mathrm{m}^{-3}\right)\end{array}$ & $\begin{array}{r}\text { Distance } \\
(\mathrm{km})\end{array}$ \\
\hline $\begin{array}{l}\text { Lille Fives } \\
\left(50.63^{\circ} \mathrm{N}, 3.09^{\circ} \mathrm{E}\right)\end{array}$ & urban & 08:00 & 62 & 07:30-08:00 & $61 \pm 6$ & 4 \\
\hline $\begin{array}{l}\text { Douai Theuriet } \\
\left(50.38^{\circ} \mathrm{N}, 3.07^{\circ} \mathrm{E}\right)\end{array}$ & urban & $08: 30$ & 68 & 08:32 & 94 & 6 \\
\hline $\begin{array}{l}\text { Saint Laurent Blangy } \\
\left(50.31^{\circ} \mathrm{N}, 2.81^{\circ} \mathrm{E}\right)\end{array}$ & suburban & $10: 00$ & 54 & $08: 37$ & 70 & 6 \\
\hline $\begin{array}{l}\text { Nogent sur Oise } \\
\left(49.28^{\circ} \mathrm{N}, 2.48^{\circ} \mathrm{E}\right)\end{array}$ & urban & $10: 15$ & 27 & $10: 18$ & 33 & 16 \\
\hline $\begin{array}{l}\text { Creil } \\
\left(49.26^{\circ} \mathrm{N}, 2.47^{\circ} \mathrm{E}\right)\end{array}$ & urban & $10: 15$ & 31 & $10: 19$ & 36 & 15 \\
\hline $\begin{array}{l}\text { Bobigny } \\
\left(48.904^{\circ} \mathrm{N}, 2.46^{\circ} \mathrm{E}\right)\end{array}$ & background & 11:00 & 20 & $10: 48$ & 43 & 6 \\
\hline $\begin{array}{l}\text { Route nationale } 2 \text { - pantin } \\
\left(48.902^{\circ} \mathrm{N}, 2.39^{\circ} \mathrm{E}\right)\end{array}$ & traffic & 11:00 & 40 & $10: 48$ & 43 & 1.2 \\
\hline $\begin{array}{l}\text { Boulevard Périphérique Est } \\
\left(48.84^{\circ} \mathrm{N}, 2.41^{\circ} \mathrm{E}\right)\end{array}$ & traffic & 11:00 & 33 & $10: 58$ & 62 & 0.2 \\
\hline
\end{tabular}

derived from lidar-photometer coupling at its closest point to the surface. Moreover, these measurements can also be considered in a joint retrieval as an additional constraint to improve the extinction coefficient, mostly in the lower part of the profile (not done in this work). Mobile measurements of particle number concentration have been performed along Lille-Palaiseau transect on 28 August 2017, from 08:00 to 11:30 UTC. From these measurements, $\mathrm{PM}_{10}, \mathrm{PM}_{2.5}$ and $\mathrm{PM}_{1}$ concentrations along the transect have been calculated. Predicted $\mathrm{PM}_{10}$ maps given by the ESMERALDA (EtudeS MultiRegionALes De l'Atmosphere) platform (http://www. esmeralda-web.fr/, last access: 30 March 2018), which is based on the chemistry-transport CHIMERE model (Menut et al., 2013) have been considered in this study for comparison with $\mathrm{PM}_{10}$ from mobile observations. The model provides hourly predictions of $\mathrm{PM}_{10}$ (along with other chemical components) on a $3 \mathrm{~km}$ resolution grid (regional domain) for each day. For our study, the model outputs assimilating the data from regional air quality stations were considered. In order to compare the $\mathrm{PM}_{10}$ variability from model to that from mobile observations, we selected the modelled $\mathrm{PM}_{10}$ corresponding to each hour spent on the road and the associated section of the mobile transect. Figure 12a depicts the spatial variability of modelled $\mathrm{PM}_{10}$ along with measured $\mathrm{PM}_{10}$ on Lille-Palaiseau route. The ATMO Hauts-de-France and AIRPARIF air quality stations closest to the investigated route are also shown in Fig. 12a. The model outputs and the mobile observations are consistent in describing the same gradient in $\mathrm{PM}_{10}$ from Lille to Paris, showing concentrations higher than $65 \mu \mathrm{gm}^{-3}$ around Lille and around $20 \mu \mathrm{g} \mathrm{m}^{-3}$ at Palaiseau. Some differences can be noted, higher concentrations from mobile measurements than from model around Lille and localised peaks along the transect and when crossing Paris ring road. One must consider that our measurements have higher resolution $(1 \mathrm{~min})$, while the model outputs correspond to the concentrations at the exact hour. Spatially, we get localised measurements along roads compared to the $3 \mathrm{~km}$ resolution of the model. Furthermore, the mobile measurements are performed along highways, which can present higher variability of the concentrations, depending on the fluctuations of the road traffic. The measured $\mathrm{PM}_{10}$ when entering the highway at Lille reach $110 \mathrm{\mu g} \mathrm{m}^{-3}$ and decrease to $40 \mu \mathrm{g} \mathrm{m}^{-3}$ at $80 \mathrm{~km}$ away from Lille, and to $25 \mu \mathrm{g} \mathrm{m}^{-3}$, when approaching Île-de-France. Higher concentrations in the range of $43-72 \mu \mathrm{g} \mathrm{m}^{-3}$ are observed along the east side of the ring-road surrounding Paris. High levels of fine particles $\left(\mathrm{PM}_{1}\right)$ around Lille and the Paris ring road indicate the influence of heavy traffic. Table 1 reports the $\mathrm{PM}_{10}$ levels recorded as $15 \mathrm{~min}$ average by air quality stations along the route and the corresponding $1 \mathrm{~min}$ aerosol spectrometer measurements from mobile observations. We checked the $\mathrm{PM}_{10}$ values from air quality station, model and our measurements at the departure point, Lille, and the agreement is excellent: $62 \mu \mathrm{g} \mathrm{m}^{-3}$ measured by Lille Fives air quality station (average between 07:00-08:00 UTC), $61 \pm 6 \mu \mathrm{g} \mathrm{m}^{-3}$ measured by the aerosol spectrometer on board the mobile platform (average between 07:30-08:00 UTC) and $61 \mu \mathrm{g} \mathrm{m}^{-3}$ from model (at 08:00 UTC). The mobile measurements were performed 
along the major highway (A1) connecting Lille to Paris, which explains the enhanced $\mathrm{PM}_{10}$ values compared to the levels measured by regional air quality monitoring stations. Taking into account all the variables, e.g. distance between the mobile and stationary measurements, type of station and temporal resolution, the $\mathrm{PM}_{10}$ concentration levels from air quality stations and our measurements are in good agreement. Regarding the comparison with the modelled $\mathrm{PM}_{10}$, leaving aside the different temporal and spatial resolution of the model vs. observations, the results are in good agreement. As ESMERALDA models the background concentrations (due to the size of the mesh), the differences observed along highways are normal, especially as higher concentrations along roads are dependent on unpredictable events like traffic jams. Our results show a possible application of the mobile platform for evaluating chemistry-transport models performances.

The aerosol extinction coefficient near surface (Fig. 12b) was obtained by applying scattering theory (Mie in our case) on the measured size distributions assuming a refractive index of $1.58--0.01 i$. Extinction as high as $0.50 \mathrm{~km}^{-1}$ was obtained on the highway at Lille, which decreased to $0.07 \mathrm{~km}^{-1}$ at Palaiseau. As mentioned previously, this information (ground level size distribution-derived extinction coefficient) can be used to constrain the retrieval of extinction coefficient profiles at near surface level and will be implemented in a future version of our processing system.

\subsection{Joint inversion of in situ and remote sensing measurements}

This part exemplifies how the in situ and remote sensing data can be used in a joint inversion in order to derive extinction coefficient profiles down to the surface level. First, the inversion of lidar data was done using the AOD constraint as described in Sect. 2.2.3. Then extinction coefficients at ground level were computed for the measured size distributions by means of a Mie scattering code, assuming a constant value of $1.53-0.01 i$ for the refractive index. This value, typical for urban haze, was chosen according to the study of Skupin et al. (2016). We applied no correction for the relative humidity effect as the values recorded along the transect were under $30 \%$. The calculated extinction coefficients from in situ data were then used to constrain the extinction profile at the surface. A linear interpolation was applied between $300 \mathrm{~m}$ a.g.l. and the surface level and the profile of extinction was iterated until the AOD from lidar matched with the one measured by the sun photometer. The extinction profiles derived with this method are shown in Fig. 13. This is an example of mobile measurements along the roads (mostly highway) between Saint-Michel l'Observatoire $\left(43.93^{\circ} \mathrm{N}, 5.71^{\circ} \mathrm{E}\right)$ and Valence $\left(45.25^{\circ} \mathrm{N}, 4.83^{\circ} \mathrm{E}\right)$, France, on 7 July 2017 . Extinction varied between 0.03 and $0.22 \mathrm{~km}^{-1}$ and transport of aerosols in the free troposphere can be observed up to $5 \mathrm{~km}$. Uncertainties on the extinction computed at ground level are related

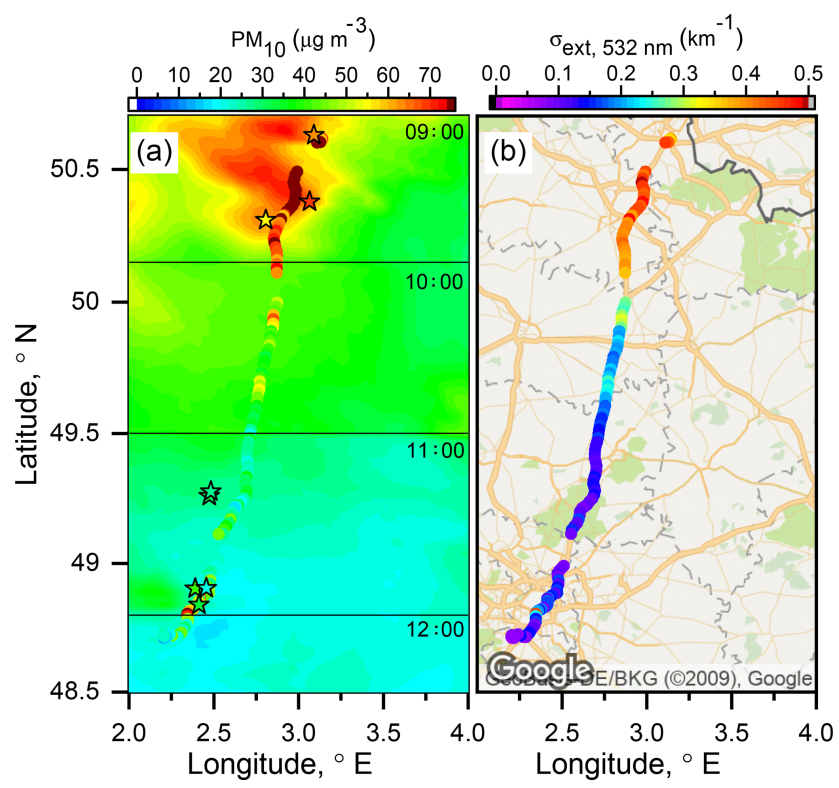

Figure 12. Spatial variability of (a) modelled $\mathrm{PM}_{10}$ concentrations and $\mathrm{PM}_{10}$ measured by mini-WRAS during mobile observations along Lille-Palaiseau transect on 28 August 2017. Air quality stations along the road are marked with colour mapped stars. The colour map is the same for both the measured and the modelled $\mathrm{PM}_{10}$ concentrations. (b) Extinction coefficient at $532 \mathrm{~nm}$ at ground level computed using Mie calculations on aerosol spectrometer data.

to the vertical and horizontal inhomogeneities in the aerosol distribution, the use of a constant and non-appropriate refractive index for the scattering calculations and the assumption on the shape of the particles. A joint experiment with scattering and absorption measurements is needed in order to quantify these uncertainties.

\section{Discussion}

In its current status MAMS is an operational vehicle-based mobile system, ready to be used for different aerosol studies and applications. Paving the way towards automation, nearreal time data processing and visualisation tools that would allow fast access to the spatial variability of aerosol properties along roads, are under development. Moreover, new capabilities at the instrumental level, such as sky radiance measurements for the sun photometer and spectral and depolarisation measurements for the lidar, are planned to be integrated in the mobile system, allowing a better characterisation of the atmospheric variability. Measurements of spectral AOD with 0.02 uncertainty are achieved with the sun photometer, while extinction coefficient profiles with an uncertainty of 15-25\% and mass concentrations profiles with an uncertainty of 35-40\% can be derived from the synergy of different instruments on-board the mobile system. These uncertainties can be reduced if we can better characterise 


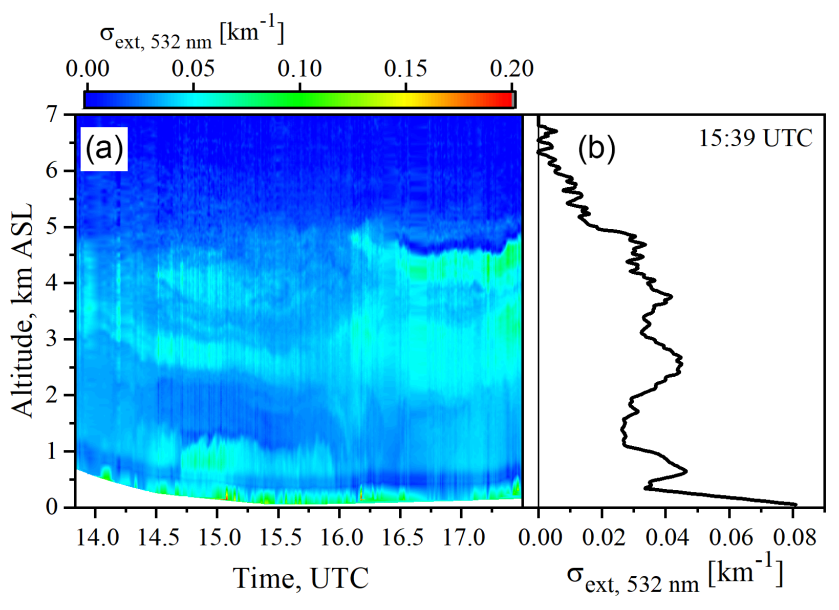

Figure 13. (a) Spatio-temporal variability of extinction coefficient derived from the joint inversion of in situ and remote sensing data and (b) example of extinction profile along the mobile transect at 15:36 UTC. The illustrated example corresponds to mobile measurements performed on 7 July 2017 from Saint-Michel

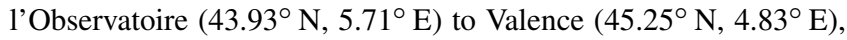
France.

aerosols microphysical and optical properties with the help of improvement and upgrade of measurement capabilities. Regarding the operation of the mobile system, generally, the participation of two operators is advised for performing mobile campaigns. The system being quite autonomous, only one driver is sometimes sufficient as follow-up of the ongoing measurements can be achieved through remote access software. The advantage of the described mobile system is its great flexibility, being able to be deployed for on-road measurements with no or little preparation beforehand, compared to airborne campaigns that require more administrative permissions and that are more difficult to set up. In addition, the system is cost-effective compared to the organization of extensive campaigns, which require more financial and human resources. Owing to the ease of its operation, the instrumented van can be deployed in case of sudden events necessitating fast reactivity, e.g. pollution and fire events, transport of dust, intrusion of volcanic ash etc. as well as for collecting vertical and surface data, which are important for modelling. The utility of the mobile system for applications such as intercomparison with other lidars and sunphotometers in operational networks, i.e. EARLINET and AERONET, has been shown in this work. The validation of satellite-derived products, e.g. MODIS AOD, has been exemplified through comparison with mobile sun photometer measurements. Moreover, the use for validation of chemistry-transport models outputs has been illustrated through comparisons at fixed location (Lille) between profiles of lidar-sun-photometer derived parameters and dust model products. In addition, the assessment of mobile measurements of $\mathrm{PM}_{10}$ vs. modelled
$\mathrm{PM}_{10}$ at surface level showed interest for air quality model validation.

Near real-time visualisation tools of all data sets are under development. On the one hand, data is planned to be displayed on a dedicated webpage and on the other hand, a desktop-based analysis software (iAAMS - Automatic Aerosol Monitoring Station) will collect all the measurements and display AOD, Angstrom Exponent, lidar RCS and extinction coefficient variability during field campaigns. Nevertheless, complex case studies remain a challenge and require post-analysis. The mobile system is versatile, providing flexibility in adding other instruments to the vehicle for specific campaigns. The integration of a second microlidar with two wavelengths and polarisation channel is envisaged, which will help in the analysis of complex aerosol situations. Furthermore, sky-scanning possibility will be integrated as feature for the next generation PLASMA sun photometer. Once these upgrades will be completed, the use of more advanced algorithms such as GRASP/GARRLiC (Lopatin et al., 2013) will give access to the vertical separation of aerosol fine and coarse modes and of absorption properties.

\section{Conclusions}

This paper describes MAMS (Mobile Aerosol Monitoring System), a ground-based, lightweight, mobile exploratory platform dedicated to the measurements of atmospheric aerosols properties, designed for both stationary and mobile measurements during the vehicle's motion. Its uniqueness consists in combining remote sensing and in situ instruments for investigating the vertical and spatial variability of aerosol properties. At this time, no other atmospheric mobile laboratory combines lidar, sun photometer and aerosol spectrometer. Measurements on-board include profiles of attenuated backscatter, extinction AOD, particle size distribution in the range of $0.01-30 \mu \mathrm{m}$ and mass concentrations $\left(\mathrm{PM}_{1}\right.$, $\mathrm{PM}_{2.5}, \mathrm{PM}_{10}$ ) at surface level. Aerosol properties such as total column volume size distribution, extinction coefficient and mass concentration profiles as well as extinction coefficient at ground level are derived from the synergy of different measurements.

In this paper, the performance of the remote sensing instruments on-board the vehicle has been assessed by comparison with instruments in reference networks such as AERONET and EARLINET. Uncertainties has been also evaluated and discussed.

Over the period 2016-2017, more than 20 mobile campaigns in France and one collaborative campaign in the North China Plain have been conducted. In this work we present two case studies meant to show the capabilities and applications of the mobile system. The first case study is focused on the mobile measurements between a continental (Lille) and a coastal (Dunkerque) site, when variations of AOD at $440 \mathrm{~nm}$ from 0.4 to 0.8 , along with a high variability of aerosol struc- 
tures vertically, over a distance of $80 \mathrm{~km}$ travelled in around $1 \mathrm{~h}$, have been recorded. Dust transport in the range $2-5 \mathrm{~km}$ altitude, added to a significant local pollution event at surface level, illustrate an interesting case of spatial and vertical variability. This case exemplifies the use of the synergy of lidar-sun-photometer measurements. The second case study, focused on in situ data and a comparison with an air quality model, showed a clear horizontal gradient in $\mathrm{PM}_{10}$ concentration between Lille and Paris, which was consistent in both observations and model.

Data availability. Data used in this paper are available upon request to the corresponding author.

Author contributions. PG, SV, TP, LB and RL conceived the concept of the mobile system. RL designed and implemented mechanical adjustments to the vehicle. PG, IEP, TP and LB conceived the experiments. IEP conducted the experiments, analysed the data, prepared the figures and wrote the manuscript. TP, LB and FU conducted the experiment(s). PG and SV supervised the work and contributed to the writing of the manuscript. CD and FD supported the data processing. AM developed the lidar-sun-photometer inversion code and IEP contributed to its evolution. BT provided expertise in GRASP-AOD inversion code. CD developed the PLASMA acquisition software and helped solving technical issues. MC provided the aerosol spectrometer instrument. NPS provided the air quality model data. CP provided the IPRAL lidar data. All authors reviewed the manuscript.

Competing interests. The authors declare that they have no conflict of interest.

Acknowledgements. We wish to thank ANRT France and CIMEL Electronique for supporting the research development on the mobile system and the CaPPA project (Chemical and Physical Properties of the Atmosphere) for the financial support. CaPPA project is funded by the French National Research Agency (ANR) through the PIA (Programme d'Investissement d'Avenir) under contract ANR-11-LABX-0005-01 and by the Regional Council Hauts-de-France and the EU. We also thank ATMO Hauts-deFrance and AIRPARIF for the $\mathrm{PM}_{10}$ data, Service National d'Observation PHOTONS/AERONET from INSU/CNRS for the Cimel CE318 sun photometer data processing and calibration and we thank Sara Basart from BSC for providing the dust model data. The ACTRIS-FR research infrastructure is also acknowledged for financial support.

Edited by: Andrew Sayer

Reviewed by: two anonymous referees

\section{References}

Ackermann, J.: The extinction-to-backscatter ratio of tropospheric aerosol: A numerical study, J. Atmos. Ocean. Tech., 15, 1043-1050, https://doi.org/10.1175/15200426(1998)015<1043:TETBRO>2.0.CO;2, 1998.

Ansmann, A., Wagner, F., Althausen, D., Müller, D., Herber, A., and Wandinger, U.: European pollution outbreaks during ACE 2: Lofted aerosol plumes observed with Raman lidar at the Portuguese coast, J. Geophys. Res.-Atmos., 106, 20725-20733, https://doi.org/10.1029/2000JD000091, 2001.

Berkhout, A. J. C., Hoff, G. R., and Van Der Gast, L. F. L.: Lidar Measurements of Industrial Benzene Emissions, edited by: Gross, B., Moshary, F., and Arend, M., EPJ Web Conf., 119, 26005, https://doi.org/10.1051/epjconf/201611926005, 2016.

Berkoff, T. A., Welton, E. J., Campbell, J. R., Scott, V. S., and Spinhirine, J. D.: Investigation of overlap correction techniques for the micro-pulse lidar network (MPLNET), IGARSS 2003, IEEE Int. Geosci. Remote Sens. Symp., 1, 4395-4397, https://doi.org/10.1109/IGARSS.2003.1295527, 2003.

Bovchaliuk, V., Goloub, P., Podvin, T., Veselovskii, I., Tanre, D., Chaikovsky, A., Dubovik, O., Mortier, A., Lopatin, A., Korenskiy, M., and Victori, S.: Comparison of aerosol properties retrieved using GARRLiC, LIRIC, and Raman algorithms applied to multi-wavelength lidar and sun/sky-photometer data, Atmos. Meas. Tech., 9, 3391-3405, https://doi.org/10.5194/amt-9-33912016, 2016.

Boyouk, N., Léon, J. F., Delbarre, H., Augustin, P., and Fourmentin, M.: Impact of sea breeze on vertical structure of aerosol optical properties in Dunkerque, France, Atmos. Res., 101, 902-910, https://doi.org/10.1016/j.atmosres.2011.05.016, 2011.

Bravo-Aranda, J. A., Belegante, L., Freudenthaler, V., AladosArboledas, L., Nicolae, D., Granados-Muñoz, M. J., GuerreroRascado, J. L., Amodeo, A., D’Amico, G., Engelmann, R., Pappalardo, G., Kokkalis, P., Mamouri, R., Papayannis, A., NavasGuzmán, F., Olmo, F. J., Wandinger, U., Amato, F., and Haeffelin, M.: Assessment of lidar depolarization uncertainty by means of a polarimetric lidar simulator, Atmos. Meas. Tech., 9, 49354953, https://doi.org/10.5194/amt-9-4935-2016, 2016.

Bukowiecki, N., Dommen, J., Prévôt, A. S. H., Richter, R., Weingartner, E., and Baltensperger, U.: A mobile pollutant measurement laboratory - Measuring gas phase and aerosol ambient concentrations with high spatial and temporal resolution, Atmos. Environ., 36, 5569-5579, https://doi.org/10.1016/S13522310(02)00694-5, 2002.

Bush, S. E., Hopkins, F. M., Randerson, J. T., Lai, C.-T., and Ehleringer, J. R.: Design and application of a mobile groundbased observatory for continuous measurements of atmospheric trace gas and criteria pollutant species, Atmos. Meas. Tech., 8, 3481-3492, https://doi.org/10.5194/amt-8-3481-2015, 2015.

Campbell, J. R., Hlavka, D. L., Welton, E. J., Flynn, C. J., Turner, D. D., Spinhirne, J. D., Stanley, S., and Hwang, I. H.: Full-time, eye-safe cloud and aerosol lidar observation at atmospheric radiation measurement program sites: Instruments and data processing, J. Atmos. Ocean. Tech., 19, 431-442, https://doi.org/10.1175/15200426(2002)019<0431:FTESCA>2.0.CO;2, 2002.

Chazette, P.: The monsoon aerosol extinction properties at Goa during INDOEX as measured with lidar, J. Geophys. Res., 108, 4187, https://doi.org/10.1029/2002JD002074, 2003. 
Chazette, P., David, C., Lefrere, J., Godin, S., Pelon, J., and Mégie, G.: Comparative lidar study of the optical, geometrical, and dynamical properties of stratospheric postvolcanic aerosols, following the eruptions of El Chichon and Mount Pinatubo, J. Geophys. Res., 100, 23195-23207, https://doi.org/10.1029/95JD02268, 1995.

Chazette, P., Marnas, F., and Totems, J.: The mobile Water vapor Aerosol Raman LIdar and its implication in the framework of the HyMeX and ChArMEx programs: application to a dust transport process, Atmos. Meas. Tech., 7, 1629-1647, https://doi.org/10.5194/amt-7-1629-2014, 2014.

Cheng, Y.-H. and Lin, Y.-L.: Measurement of Particle Mass Concentrations and Size Distributions in an Underground Station, Aerosol Air Qual. Res., 10, 22-29, https://doi.org/10.4209/aaqr.2009.05.0037, 2010.

Chiang, C.-W., Das, S. K., Chiang, H.-W., Nee, J.-B., Sun, S.H., Chen, S.-W., Lin, P.-H., Chu, J.-C., Su, C.-S., and Su, L.S.: A new mobile and portable scanning lidar for profiling the lower troposphere, Geosci. Instrum. Method. Data Syst., 4, 3544, https://doi.org/10.5194/gi-4-35-2015, 2015.

Dieudonné, E., Chazette, P., Marnas, F., Totems, J., and Shang, X.: Lidar profiling of aerosol optical properties from Paris to Lake Baikal (Siberia), Atmos. Chem. Phys., 15, 5007-5026, https://doi.org/10.5194/acp-15-5007-2015, 2015.

Dou, X., Han, Y., Sun, D., Xia, H., Shu, Z., Zhao, R., Shangguan, M., and Guo, J.: Mobile Rayleigh Doppler lidar for wind and temperature measurements in the stratosphere and lower mesosphere, Opt. Exp., 22, A1203, https://doi.org/10.1364/OE.22.0A1203, 2014.

Drewnick, F., Böttger, T., von der Weiden-Reinmüller, S.-L., Zorn, S. R., Klimach, T., Schneider, J., and Borrmann, S.: Design of a mobile aerosol research laboratory and data processing tools for effective stationary and mobile field measurements, Atmos. Meas. Tech., 5, 1443-1457, https://doi.org/10.5194/amt-5-14432012, 2012.

Dubovik, O., Lapyonok, T., Litvinov, P., Herman, M., Fuertes, D., Ducos, F., Torres, B., Derimian, Y., Huang, X., Lopatin, A., Chaikovsky, A., Aspetsberger, M., and Federspiel, C.: GRASP: a versatile algorithm for characterizing the atmosphere, SPIE Newsroom, 2-5, https://doi.org/10.1117/2.1201408.005558, 2014.

Fernald, F. G.: Analysis of atmospheric lidar observations: some comments, Appl. Opt., 23, 5, https://doi.org/10.1364/AO.23.000652, 1984.

Freudenthaler, V., Matthias, V., Amodeo, A., Balis, D., Calpini, B., Chourdakis, G., Comeron, A., Delaval, A., De Tomasi, F., Eixmann, R., Komguem, L., Kreipl, S., Matthey, R., Mattis, I., Rizi, V., Rodriguez, J., Wang, X., Wiegner, M., and Bösenberg, J.: Intercomparison of 21 aerosol lidar systems in the frame of EARLINET, in: Lidar Remote Sensing in Atmosphere and Earth Sciences, proceedings of the XXI International Laser Radar Conference, Quebec, Canada, 8-12, available at: https://www.meteo.physik.uni-muenchen.de/ st212fre/ ILRC21/freudenthaler_et_al_rev3.PDF (last access: 6 March 2018), 2002.

Freudenthaler, V., Linné, H., Chaikovski, A., Rabus, D., and Groß, S.: EARLINET lidar quality assurance tools, Atmos. Meas. Tech. Discuss., https://doi.org/10.5194/amt-2017-395, in review, 2018.
Grimm, H. and Eatough, D. J.: Aerosol measurement: The use of optical light scattering for the determination of particulate size distribution, and particulate mass, including the semi-volatile fraction, J. Air Waste Manage., 59, 101-107, https://doi.org/10.3155/1047-3289.59.1.101, 2009.

Haeffelin, M., Barthès, L., Bock, O., Boitel, C., Bony, S., Chepfer, H., Chiriaco, M., Cuesta, J., Delanoë, J., Haeffelin, M., Barthès, L., Bock, O., Boitel, C., Bony, S., Haeffelin, M., and Barth, L.: SIRTA, a ground-based atmospheric observatory for cloud and aerosol research, hal-00329353, Annales Geophysicae SIRTA, 2005.

He, Q. S., Li, C. C., Mao, J. T., Lau, A. K. H., and Li, P. R.: A study on the aerosol extinction-to-backscatter ratio with combination of micro-pulse LIDAR and MODIS over Hong Kong, Atmos. Chem. Phys., 6, 3243-3256, https://doi.org/10.5194/acp-6-32432006, 2006.

Holben, B. N., Eck, T. F., Slutsker, I., Tanré, D., Buis, J. P., Setzer, A., Vermote, E., Reagan, J. A., Kaufman, Y. J., Nakajima, T., Lavenu, F., Jankowiak, I., and Smirnov, A.: AERONET - A federated instrument network and data archive for aerosol characterization, Remote Sens. Environ., 66, 1-16, https://doi.org/10.1016/S0034-4257(98)00031-5, 1998.

Hussein, T., Boor, B. E., dos Santos, V. N., Kangasluoma, J., Petäjä, T., and Lihavainen, H.: Mobile aerosol measurement in the Eastern Mediterranean - A utilization of portable instruments, Aerosol Air Qual. Res., 17, 1875-1886, https://doi.org/10.4209/aaqr.2016.11.0479, 2017.

Karol, Y., Tanré, D., Goloub, P., Vervaerde, C., Balois, J. Y., Blarel, L., Podvin, T., Mortier, A., and Chaikovsky, A.: Airborne sun photometer PLASMA: concept, measurements, comparison of aerosol extinction vertical profile with lidar, Atmos. Meas. Tech., 6, 2383-2389, https://doi.org/10.5194/amt-6-2383-2013, 2013.

Khaykin, S. M., Godin-Beekmann, S., Hauchecorne, A., Pelon, J., Ravetta, F., and Keckhut, P.: Stratospheric Smoke With Unprecedentedly High Backscatter Observed by Lidars Above Southern France, Geophys. Res. Lett., 45, 1639-1646, https://doi.org/10.1002/2017GL076763, 2018.

Klett, J. D.: Stable analytical inversion solution for processing lidar returns, Appl. Opt., 20, 211-220, https://doi.org/10.1364/AO.20.000211, 1981.

Kunz, G. J. and de Leeuw, G.: Inversion of lidar signals with the slope method, Appl. Opt., 32, 3249-3256, https://doi.org/10.1364/AO.32.003249, 1993.

Léon, J.-F., Derimian, Y., Chiapello, I., Tanrè, D., Podvin, T., Chatenet, B., Diallo, A., and Deroo, C.: Aerosol vertical distribution and optical properties over M'Bour $\left(16.96^{\circ} \mathrm{W} ; 14.39^{\circ} \mathrm{N}\right)$, Senegal from 2006 to 2008, Atmos. Chem. Phys., 9, 9249-9261, https://doi.org/10.5194/acp-9-9249-2009, 2009.

Levin, E. J. T., Kreidenweis, S. M., McMeeking, G. R., Carrico, C. M., Collett, J. L., and Malm, W. C.: Aerosol physical, chemical and optical properties during the Rocky Mountain Airborne Nitrogen and Sulfur study, Atmos. Environ., 43, 1932-1939, https://doi.org/10.1016/j.atmosenv.2008.12.042, 2009.

Levy, R. C., Mattoo, S., Munchak, L. A., Remer, L. A., Sayer, A. M., Patadia, F., and Hsu, N. C.: The Collection 6 MODIS aerosol products over land and ocean, Atmos. Meas. Tech., 6, 29893034, https://doi.org/10.5194/amt-6-2989-2013, 2013.

Lewandowski, P. A., Eichinger, W. E., Holder, H., Prueger, J., Wang, J., and Kleinman, L. I.: Vertical distribution of 
aerosols in the vicinity of Mexico City during MILAGRO2006 Campaign, Atmos. Chem. Phys., 10, 1017-1030, https://doi.org/10.5194/acp-10-1017-2010, 2010.

Lopatin, A., Dubovik, O., Chaikovsky, A., Goloub, P., Lapyonok, T., Tanré, D., and Litvinov, P.: Enhancement of aerosol characterization using synergy of lidar and sun-photometer coincident observations: the GARRLiC algorithm, Atmos. Meas. Tech., 6, 2065-2088, https://doi.org/10.5194/amt-6-2065-2013, 2013.

Marchant, C. C.: Aglite lidar: a portable elastic lidar system for investigating aerosol and wind motions at or around agricultural production facilities, J. Appl. Remote Sens., 3, 033511, https://doi.org/10.1117/1.3097928, 2009.

Menut, L., Bessagnet, B., Khvorostyanov, D., Beekmann, M., Blond, N., Colette, A., Coll, I., Curci, G., Foret, G., Hodzic, A., Mailler, S., Meleux, F., Monge, J.-L., Pison, I., Siour, G., Turquety, S., Valari, M., Vautard, R., and Vivanco, M. G.: CHIMERE 2013: a model for regional atmospheric composition modelling, Geosci. Model Dev., 6, 981-1028, https://doi.org/10.5194/gmd-6-981-2013, 2013.

Mortier, A.: Aerosol Spatial Distribution During DRAGON Experiment As Seen by a Mobile GroundBased LiDAR-Sunphotometer System - Preliminary Results, Conference paper ILRC, available at: https://www.researchgate.net/publication/273136571 (last access: 8 August 2018), 2012.

Mortier, A.: Tendances et variabilites de l'aerosol atmospherique a l'aide du couplage Lidar/Photometre sur les sites de Lille et Dakar, University of Lille, 2013.

Mortier, A., Goloub, P., Podvin, T., Deroo, C., Chaikovsky, A., Ajtai, N., Blarel, L., Tanre, D., and Derimian, Y.: Detection and characterization of volcanic ash plumes over Lille during the Eyjafjallajökull eruption, Atmos. Chem. Phys., 13, 3705-3720, https://doi.org/10.5194/acp-13-3705-2013, 2013.

Mortier, A., Goloub, P., Derimian, Y., Tanré, D., Podvin, T., Blarel, L., Deroo, C., Marticorena, B., Diallo, A., and Ndiaye, T.: Climatology of aerosol properties and clear-sky shortwave radiative effects using lidar and sun photometer observations in the Dakar site, J. Geophys. Res., 121, 6489-6510, https://doi.org/10.1002/2015JD024588, 2016.

Niemi, J. V., Saarikoski, S., Tervahattu, H., Mäkelä, T., Hillamo, R., Vehkamäki, H., Sogacheva, L., and Kulmala, M.: Changes in background aerosol composition in Finland during polluted and clean periods studied by TEM/EDX individual particle analysis, Atmos. Chem. Phys., 6, 5049-5066, https://doi.org/10.5194/acp6-5049-2006, 2006.

Pal, S., Xueref-Remy, I., Ammoura, L., Chazette, P., Gibert, F., Royer, P., Dieudonné, E., Dupont, J. C., Haeffelin, M., Lac, C., Lopez, M., Morille, Y., and Ravetta, F.: Spatiotemporal variability of the atmospheric boundary layer depth over the Paris agglomeration: An assessment of the impact of the urban heat island intensity, Atmos. Environ., 63, 261-275, https://doi.org/10.1016/j.atmosenv.2012.09.046, 2012.

Pappalardo, G., Amodeo, A., Apituley, A., Comeron, A., Freudenthaler, V., Linné, H., Ansmann, A., Bösenberg, J., D’Amico, G., Mattis, I., Mona, L., Wandinger, U., Amiridis, V., AladosArboledas, L., Nicolae, D., and Wiegner, M.: EARLINET: towards an advanced sustainable European aerosol lidar network, Atmos. Meas. Tech., 7, 2389-2409, https://doi.org/10.5194/amt7-2389-2014, 2014.
Pelon, J., Mallet, M., Mariscal, A., Goloub, P., Tanré, D., Bou Karam, D., Flamant, C., Haywood, J., Pospichal, B., and Victori, S.: Microlidar observations of biomass burning aerosol over Djougou (Benin) during African Monsoon Multidisciplinary Analysis Special Observation Period 0: Dust and Biomass-Burning Experiment, J. Geophys. Res., 113, D00C18, https://doi.org/10.1029/2008JD009976, 2008.

Raut, J.-C. and Chazette, P.: Assessment of vertically-resolved $\mathrm{PM}_{10}$ from mobile lidar observations, Atmos. Chem. Phys., 9, 8617-8638, https://doi.org/10.5194/acp-9-8617-2009, 2009.

Raut, J.-C., Chazette, P., Haywood, J., and Royer, P.: Lidar observations by circling the London orbital motorway, AGU Fall Meeting, available at: https://www.researchgate.net/publication/ 253096419_Lidar_observations_by_circling_the_London_ orbital_motorway (last access: 8 August 2018), 2009.

Royer, P., Chazette, P., Sartelet, K., Zhang, Q. J., Beekmann, M., and Raut, J.-C.: Comparison of lidar-derived $\mathrm{PM}_{10}$ with regional modeling and ground-based observations in the frame of MEGAPOLI experiment, Atmos. Chem. Phys., 11, 1070510726, https://doi.org/10.5194/acp-11-10705-2011, 2011.

Skupin, A., Ansmann, A., Engelmann, R., Seifert, P., and Müller, T.: Four-year long-path monitoring of ambient aerosol extinction at a central European urban site: dependence on relative humidity, Atmos. Chem. Phys., 16, 1863-1876, https://doi.org/10.5194/acp-16-1863-2016, 2016.

Smirnov, A., Holben, B. N., Eck, T. F., Dubovik, O., and Slutsker, I.: Cloud-screening and quality control algorithms for the AERONET database, Remote Sens. Environ., 73, 337-349, https://doi.org/10.1016/S0034-4257(00)00109-7, 2000.

Smirnov, A., Holben, B. N., Slutsker, I., Giles, D. M., McClain, C. R., Eck, T. F., Sakerin, S. M., Macke, A., Croot, P., Zibordi, G., Quinn, P. K., Sciare, J., Kinne, S., Harvcy, M., Smyth, T. J., Piketh, S., Zielinski, T., Proshutinsky, A., Goes, J. I., Nelson, N. B., Larouche, P., Radionov, V. F., Goloub, P., Krishna Moorthy, K., Matarrese, R., Robertson, E. J., and Jourdin, F.: Maritime Aerosol Network as a component of Aerosol Robotic Network, J. Geophys. Res.-Atmos., 114, 1-10, https://doi.org/10.1029/2008JD011257, 2009.

Swietlicki, E., Hansson, H. C., Hämeri, K., Svenningsson, B., Massling, A., Mcfiggans, G., Mcmurry, P. H., Petäjä, T., Tunved, P., Gysel, M., Topping, D., Weingartner, E., Baltensperger, U., Rissler, J., Wiedensohler, A., and Kulmala, M.: Hygroscopic properties of submicrometer atmospheric aerosol particles measured with H-TDMA instruments in various environments - A review, Tellus B, 60, 432-469, https://doi.org/10.1111/j.16000889.2008.00350.x, 2008.

Torres, B., Dubovik, O., Fuertes, D., Schuster, G., Cachorro, V. E., Lapyonok, T., Goloub, P., Blarel, L., Barreto, A., Mallet, M., Toledano, C., and Tanré, D.: Advanced characterisation of aerosol size properties from measurements of spectral optical depth using the GRASP algorithm, Atmos. Meas. Tech., 10, 3743-3781, https://doi.org/10.5194/amt-10-3743-2017, 2017.

Unga, F.: Investigation of atmospheric aerosol mixing state effect on measured and retrieved optical characteristics?: an approach integrating individual particle analysis, remote sensing and numerical simulations, University of Lille, 2017.

Veselovskii, I., Goloub, P., Podvin, T., Bovchaliuk, V., Derimian, Y., Augustin, P., Fourmentin, M., Tanre, D., Korenskiy, M., Whiteman, D. N., Diallo, A., Ndiaye, T., Kolgotin, A., and Dubovik, 
O.: Retrieval of optical and physical properties of African dust from multiwavelength Raman lidar measurements during the SHADOW campaign in Senegal, Atmos. Chem. Phys., 16, 70137028, https://doi.org/10.5194/acp-16-7013-2016, 2016.

Wagner, T., Ibrahim, O., Shaiganfar, R., and Platt, U.: Mobile MAX-DOAS observations of tropospheric trace gases, Atmos. Meas. Tech., 3, 129-140, https://doi.org/10.5194/amt-3-1292010, 2010.

Wang, W., Mao, F., Pan, Z., Du, L., and Gong, W.: Validation of VIIRS AOD through a comparison with a sun photometer and MODIS AODs over Wuhan, Remote Sens., 9, 403, https://doi.org/10.3390/rs9050403, 2017.

Weber, K., Eliasson, J., Vogel, A., Fischer, C., Pohl, T., van Haren, G., Meier, M., Grobéty, B., and Dahmann, D.: Airborne insitu investigations of the Eyjafjallajökull volcanic ash plume on iceland and over north-western Germany with light aircrafts and optical particle counters, Atmos. Environ., 48, 9-21, https://doi.org/10.1016/j.atmosenv.2011.10.030, 2012.

Weijers, E. P., Khlystov, A. Y., Kos, G. P. A., and Erisman, J. W.: Variability of particulate matter concentrations along roads and motorways determined by a moving measurement unit, Atmos. Environ., 38, 2993-3002, https://doi.org/10.1016/j.atmosenv.2004.02.045, 2004.

Weimer, S., Mohr, C., Richter, R., Keller, J., Mohr, M., Prévôt, A. S. H., and Baltensperger, U.: Mobile measurements of aerosol number and volume size distributions in an Alpine valley: Influence of traffic versus wood burning, Atmos. Environ., 43, 624-630, https://doi.org/10.1016/j.atmosenv.2008.10.034, 2009.
Welton, E. J. and Campbell, J. R.: Micropulse lidar signals: Uncertainty analysis, J. Atmos. Ocean. Tech., 19, 2089-2094, https://doi.org/10.1175/15200426(2002)019<2089:MLSUA>2.0.CO;2, 2002.

Welton, E. J., Campbell, J. R., Berkoff, T. A., Valencia, S., Spinhirne, J. D., Holben, B., Tsay, S.-C., and Schmid, B.: The NASA Micro-Pulse Lidar Network (MPLNET): an overview and recent results MPLNET, Red de lidares Micropulso de la NASA: Descripción general y resultados recientes, 39 pp., available at: https://pdfs.semanticscholar.org/ 845d/87d5bffa1c87de2eacfc361e6a613950c3b0.pdf (last access: 5 March 2018), 2005.

Wu, F. C., Xie, P. H., Li, A., Chan, K. L., Hartl, A., Wang, Y., Si, F. Q., Zeng, Y., Qin, M., Xu, J., Liu, J. G., Liu, W. Q., and Wenig, M.: Observations of $\mathrm{SO}_{2}$ and $\mathrm{NO}_{2}$ by mobile DOAS in the Guangzhou eastern area during the Asian Games 2010, Atmos. Meas. Tech., 6, 2277-2292, https://doi.org/10.5194/amt-62277-2013, 2013. 